\title{
Compact Telescoping Surface Array for Mars Solar Power
}

\author{
Richard Pappa* ${ }^{*}$ Geoff Rose ${ }^{\dagger}$, Matt Chamberlain ${ }^{\dagger}$, and Dave Paddock ${ }^{\ddagger}$ \\ NASA Langley Research Center, Hampton, VA 23681 \\ and \\ Martin Mikulas ${ }^{\S}$ \\ National Institute of Aerospace, Hampton, VA 23666
}

\begin{abstract}
This paper describes a lightweight, large-area solar array concept for Mars surface power called the Compact Telescoping Surface Array (CTSA). The design is derived from the Compact Telescoping Array (CTA) proposed in 2015 for high-power spacecraft. The CTSA deploys horizontally from Mars landers, provides $1000 \mathrm{~m}^{2}$ of solar cell area, and generates about 50-80 kW daytime and $10 \mathrm{~kW}$ nighttime power (from energy storage) near the equator with clear skies. The total mass is about $1500 \mathrm{~kg}$, and the stowed volume is about $10 \mathrm{~m}^{3}$, equivalent to $200 \mathrm{~W} / \mathrm{kg}$ and $30 \mathrm{~kW} / \mathrm{m}^{3}$ at 1 astronomical unit (AU) from the sun. These challenging mass and volume goals require compact, lightweight structures to deploy and tension thin solar cell blankets in the Mars $0.38 \mathrm{~g}$ gravity field. Other features include singleaxis rotation for daily or seasonal sun tracking, dust shedding, and feathering in high winds and sufficient strength for sustained $40 \mathrm{~m} / \mathrm{s}$ winds in dust storms and brief $100 \mathrm{~m} / \mathrm{s}$ winds in dust devils (dynamic pressure of $120 \mathrm{~Pa}$ ). Based on preliminary design and analysis reported in the paper, CTSA appears to be a feasible approach for $1000 \mathrm{~m}^{2}$-class Mars solar arrays that autonomously deploy from landers prior to human arrival.
\end{abstract}

\section{Introduction}

$\mathrm{E}^{\mathrm{I}}$ ectrical power for human exploration of Mars will be provided by some combination of solar, nuclear, chemical, and geothermal sources. Although recent developments have occurred in 1-10 kW nuclear fission technology for Mars surface power, ${ }^{1}$ little attention has been given to Mars solar power systems since the Mars Design Reference Architecture 5.0 study in $2009 .{ }^{2}$ Recognizing new developments in large lightweight $30-50 \mathrm{~kW}$ solar arrays for space missions, with the successful demonstration of the Orbital ATK MegaFlex and Deployable Space Systems ROSA, ${ }^{3}$ the NASA Space Technology Mission Directorate (STMD) is reexamining solar arrays for prime electrical power on human Mars missions. The timeline for this renewed Mars solar power development shows comparison with nuclear sources occurring in the early 2020s to allow sufficient time for engineering design and qualification of the preferred power solution for initial Mars missions in the early 2030s. ${ }^{4,5}$

A recent study of power needs for Mars exploration noted that systems used on previous surface missions (Pathfinder, Spirit and Opportunity, Phoenix, and Mars Science Laboratory) are insufficient for future human missions. ${ }^{6}$ The following requirements were identified for initial Mars surface power: 1) up to $40 \mathrm{~kW}$ day/night continuous power; 2) power for In-Situ Resource Utilization (ISRU) propellant production prior to crew arrival; 3) power for landers, habitats, life support, and rover recharging; 4) the need for compact stowage, robotic deployment, surviving multiple crew campaigns (at least 10 years), and long distance power distribution; and 5) the ability to validate proposed systems for Mars entry, descent, and landing (EDL), ISRU, and surface power in a mid/late 2020s

\footnotetext{
${ }^{*}$ Research Engineer, Structural Dynamics Branch, Mail Stop 230, AIAA Associate Fellow.

${ }^{+}$Research Engineer, Structural Dynamics Branch, Mail Stop 230, AIAA Senior Member.

${ }^{\ddagger}$ Mechanical Engineer, Mechanical Systems Branch, Mail Stop 432.

${ }^{\S}$ Senior Research Fellow, AIAA Fellow.
} 
demonstration mission. Furthermore, it was mentioned that although Mars is the primary target, suitability of new power technologies for the Moon is also desired.

\section{Solar Array Design Guidelines}

The assumed solar power architecture uses $10 \mathrm{~kW}$-class solar arrays and regenerative fuel cells for energy storage on early Mars landers. ${ }^{7}$ Nearby landers might be connected to form a power grid. The best way to stow and then deploy these large solar arrays prior to human arrival was a key aspect of the study. Figure 1 shows typical lander concepts. Only vertical landers, which stow vertically in the launch shroud, were considered in the study. Note that most of the lander volume is occupied by cargo other than the power system, which implies the solar power system should stow as compactly as possible. Of course, minimizing the mass of all hardware for Mars is also paramount. The Compact Telescoping Surface Array (CTSA) addresses these key objectives.

Table 1 lists 20 solar array design guidelines developed in collaboration with Mars mission architects at the NASA Johnson Space Center (JSC) ${ }^{7}$ and other locations. Two key requirements for the solar arrays are to autonomously deploy from Mars landers and have about $1000 \mathrm{~m}^{2}$ of solar cell area. This size is sufficient for Mars solar array technology development and for generating at least $10 \mathrm{~kW}$ of day/night continuous power at low-latitude sites with clear skies. Because more solar array area is needed at higher latitudes or under dustier skies for the same power generation, a "stretch goal" of $1500 \mathrm{~m}^{2}$ area was also included. Note that the $1000-1500 \mathrm{~m}^{2}$ solar array area range was not selected by flowing down specific mission requirements, which do not exist yet for human Mars exploration. These sizes are based on engineering estimates of the correct order of magnitude of solar array area needed for plausible initial exploration missions. The solar arrays should deploy autonomously to minimize communications time with Earth, which can be as long as 48 minutes round trip. The built-in deployment controller should monitor progress and stop deployment if absolutely necessary.

The other design guidelines in Table 1 are mostly self-explanatory. The rationale for each guideline was discussed in more detail in a telecon conducted for the space community. An audio recording and charts are available from this event. $^{8}$

\section{Power Predictions}

Figure 2 shows power predictions for a $1000 \mathrm{~m}^{2}$ solar array located at the equator under clear skies. The left-hand plot shows daytime and nighttime user power available over a $24.6 \mathrm{hr}$ Martian day (sol) when the planet is farthest from the sun (aphelion), and the right-hand plot shows daytime and nighttime user power available over a complete Martian year of 668 sols. For these estimates, six solar array wings were deployed radially around a Mars lander as shown later in Fig. 7. These predictions were made by Tom Kerslake at the NASA Glenn Research Center (GRC) using a version of their legacy "SPACE" Fortran power prediction software known as the Mars Surface Electric Power System (MSEPS) ${ }^{9}$ based on atmospheric light-scattering models of the Martian atmosphere. ${ }^{10}$ Additional estimates of available power using the solar arrays with $10 \mathrm{~kW}$ regenerative fuel cells over a wider range of independent variables including landing site latitude and sky opacity (dustiness) measured by its optical depth are provided elsewhere. ${ }^{11}$

\section{Selection of a Solar Array Configuration for the Study}

Figure 3 shows the steps the team followed to select a baseline concept for a $1000 \mathrm{~m}^{2}$ Mars surface solar array. Several previously proposed concepts mostly going back 20 to 30 years were considered. ${ }^{2,12-15}$ The team also reviewed advanced spacecraft solar array concepts including UltraFlex/MegaFlex, ROSA, and CTA.

The Compact Telescoping Array (CTA) is a concept developed by NASA Langley Research Center (LaRC) in a previous study of $1 \mathrm{MW}$ solar arrays for high-power solar electric propulsion (SEP). ${ }^{16}$ For Mars surface power, the CTA was down-selected and about 10 variations of this concept were evaluated. CTA has many independent design variables that allow nearly all desired stowed and deployed geometries, meeting the strength and stiffness requirements with the same basic design. Furthermore, this design allowed for attachment of support legs to the boom segments of horizontally deployed CTA wings. This design flexibility permits CTA to be adapted for diverse missions from high- 
power SEP spacecraft to extraterrestrial surface solar power. The team also assessed innovations from several Small Business Innovative Research (SBIR) contracts with companies whose technologies might improve or complement Mars solar array development. ${ }^{17}$ For example, Angstrom Designs, Inc., in collaboration with Orbital ATK of Goleta, CA, is designing and testing prototype CTA hardware for $10 \mathrm{~kW}$-class spacecraft under SBIR Phase 2 contracts with NASA LaRC and the Air Force Research Laboratory (AFRL). ${ }^{18}$

Figure 4 shows previously proposed concepts for Martian and lunar surface solar arrays. Many disparate configurations have been proposed over the years for both destinations, having some similar requirements. ${ }^{19}$ Mission planners must understand exactly how these large solar arrays will package for launch, then deploy, and operate on Mars at anticipated landing sites. Mars solar arrays must autonomously deploy from landers, so concepts needing human or rover assistance to deploy are not feasible. The team also found in its review of prior work that details of how these structures package and deploy were usually missing.

Considering the design guidelines in Table 1, the team rated the second concept in the top row of Fig. 4 to be the most promising. This configuration is similar to how terrestrial solar arrays with horizontal single-axis sun tracking are designed. The central sheds in the sketch hold power processing equipment and batteries or regenerative fuel cells for energy storage, and they also provide end supports for the solar arrays. However, these arrays do not deploy from the lander and require cranes and cargo haulers to unload, transport, and erect. Thus, it is not an acceptable solution for initial Mars missions before construction equipment arrives. Because of the similarity of CTA with the mostpromising concept in Fig. 4, the team evaluated multiple versions of this configuration. The CTA concept was modified to package and deploy horizontally from $10 \mathrm{~m}$ diameter Mars landers, and be supported in the Mars $0.38 \mathrm{~g}$ field by fold-out legs or by overhead guy wires.

Terrestrial technology is usually not applicable or informative for space missions, but it is helpful for designing Mars solar power systems to understand preferred configurations for large terrestrial arrays. Figure 5 shows what is believed to be the largest single-axis tracking solar array ${ }^{20}$ in the world, located in Southern California near the Mexican border. This array covers about 2000 acres of land (8 million square meters) and generates about 250 megawatts of power. It is much larger than Martian solar arrays will be for the foreseeable future. However, understanding how these terrestrial behemoths operate is informative. For example, these arrays are ganged together with a bar allowing one actuator to drive the single-axis rotation on multiple rows, which improves mechanical reliability. Individual rows of solar panels run north and south, and they track the sun daily from east to west across the sky. The rows are sufficiently spaced to minimize shadowing in the morning and evening, and to simplify maintenance.

\section{Compact Telescoping Surface Array (CTSA)}

The Compact Telescoping Surface Array (CTSA) is derived from the Compact Telescoping Array (CTA) $)^{16,18}$ modified for horizontal deployment from Mars landers and able to withstand gravity and wind loadings. It must also satisfy additional design guidelines in Table 1.

Figure 6 depicts the CTA solar array concept, how it packages, and deploys. CTA is highly configurable with many independent design variables including the desired deployed wing width and length, and the stowed package dimensions. There is also much flexibility in selecting the number of telescoping boom segments, their dimensions, and resulting strength and stiffness. The telescoping segments are lightweight, open-lattice composite booms that are manufactured and tested before flight. ${ }^{21,22}$ CTA uses split blankets with its central boom centered in the plane of the two tensioned blankets, similar to the International Space Station (ISS) solar arrays. For exceptionally wide arrays, each blanket could be split lengthwise by hinging the blanket containment boxes. The blanket boxes use guy wires for mass-efficient stiffening. The boom deployment/retraction actuator resides inside the base boom segment, although exterior actuators are also possible. 


\section{A. CTSA Baseline Design}

The selection process described in the previous section led to the solar array concept referred to as the baseline Compact Telescoping Surface Array (CTSA), shown in Fig. 7 and first described at the 2017 Space Power Workshop. ${ }^{23}$ The idea is to support horizontally deployed CTA wings at one or more points along their length, allowing single-axis rotation for daily or seasonal sun tracking, dust shedding, and feathering in high winds. Note that the CTSA uses tensioned flexible blankets similar to those on the ISS solar arrays to minimize mass and packaging volume. The CTSA wings must deploy in under $0.38 \mathrm{~g}$, and survive wind gusts, deposited dust, and other Martian environments. Exactly how the large solar cell blankets, with an expected density of about $0.5 \mathrm{~kg} / \mathrm{m}^{2}$, are supported during and after deployment is the subject of on-going studies. Note that the solar array wings in Fig. 7 are spaced about 50 or 55 degrees apart, rather than 60 degrees, to allow additional space on two opposite sides of the lander for cargo unloading.

Each of the six solar array wings in the baseline design has a deployed blanket area of $167 \mathrm{~m}^{2}$, for a total area of $1000 \mathrm{~m}^{2}$. Although this size is about twice that of the recently demonstrated MegaFlex and ROSA solar arrays, ${ }^{3}$ each CTSA wing is well within state-of-the-art dimensions, as shown in Fig. 8, by comparison with the successful ISS solar array wings. Similar to the ISS arrays, the CTSA uses z-folded (fan-folded) solar cell blankets compressed between two blanket box halves for launch.

Figure 9 shows how the CTSA wings will stow and deploy from a Mars lander. Exactly how each deployment step is mechanized is still under study. Current thinking uses separate motors for deployment of the initial long-reach leg, deployment of the CTA array, and then deployment of the end leg, although the leg deployers could use passive springs and dampers. All legs include length adjusters for uneven terrain with up to 0.5 -m rocks, 15 deg slopes, and potentially hidden hazards (Design Guideline \#10 in Table 1). The solar arrays permit horizontal single-axis rotation; this mechanized system is not yet designed. Rotating the entire solar array wings requires bearings at three locations; the CTSA base on the lander, at the inner long-reach leg, and at the tip leg. A simpler approach might be to rotate each of the two blankets of the wing separately while keeping the support boom stationary. This alternative was briefly examined in the study and found feasible.

Figure 10 shows a high-fidelity rendering of the baseline solar array concept. A deployment animation of this model was created in the study and is available on request. Note that Fig. 10 shows a slightly different configuration than Figs. 7 and 9 although the idea of supporting six horizontally deployed CTA wings with legs was maintained. This concept has three legs for each wing rather than just two, with the long-reach and tip fold-down legs replaced by legs that translate with the deploying telescoping boom, settling at appropriate locations. The best way to package, secure the stowed arrays for launch, and deploy the CTSA support legs is still being studied.

\section{B. CTSA Alternative H-Configuration}

Figure 11 shows one of several ways to increase the solar array deployed area to at least $1500 \mathrm{~m}^{2}$ for increased power at higher latitudes or with dustier skies. The baseline concept in Fig. 7 uses radial solar array wings distributed around the lander because Design Guideline \#3 is "Assume no lander azimuth control." With uniformly distributed radial wings, the total solar power generated by the system is almost independent of the lander clocking angle relative to the cardinal north, east, south, and west directions. This predictability of total power generation is important if the landing azimuth (clocking angle) cannot be controlled.

However, if the landing azimuth can be controlled, which is unconfirmed, a recommendation is to switch to the alternative "H configuration" in Fig. 11, where the inner two pairs of solar arrays with $1000 \mathrm{~m}^{2}$ of area will autonomously deploy prior to crew arrival. These wings are similar to those for the baseline concept except enlarged by $50 \%$ from $167 \mathrm{~m}^{2}$ to $250 \mathrm{~m}^{2}$. The larger blankets would be more difficult to handle and deploy, but are still smaller than the blankets used successfully on the ISS shown in Fig. 8. For low-latitude sites (0-30 deg N/S), the rows of solar panels will typically run north and south and track the sun daily from east to west as does the large terrestrial solar farm shown in Fig. 5. At mid-latitude sites (30-60 deg N/S), the rows of solar panels would probably run east and west 
and point south in the northern hemisphere and north in the southern hemisphere and tilt down by latitude degrees with seasonal adjustments. This orientation is common for large terrestrial solar arrays at mid-latitudes.

The H-configuration in Fig. 11 could be expanded at both ends by adding additional pairs of $250 \mathrm{~m}^{2}$ solar array wings connected electrically, but not necessarily mechanically to the inner wings. This expansion may require crew assistance. The additional wings should be self-deploying once transported and secured at the proper locations. The H-configuration also improves CTSA and lander access for servicing and cargo off-loading. However, the additional structural members and mechanisms create new design challenges. The concept uses many combinations of folding, pivoting, rotating, and telescoping mechanisms that need iterative design and analysis to develop. Figure 12 shows a high-fidelity rendering of the alternative H-configuration solar array concept. A deployment animation of this model was created in the study and is available on request.

\section{CTSA Alternative Slide-Out and Swing-Out Concepts}

Figures 13 and 14 show additional promising variations of the H-configuration. Specifically, the sketches show how the CTSA could stow horizontally on a new lower deck dedicated to the solar arrays. This approach integrates the solar arrays and lander, providing each lander with its own self-deploying power source without using valuable cargo area. The deployed H-configuration matches that shown previously in Figs. 11 and 12. This approach offers two significant advantages over vertical stowage: 1) easier clamping of the arrays for launch, transit, and landing, and 2) a larger-diameter cargo deck. Careful planning would permit cargo offloading either before or after solar array deployment. However, this approach also has the significant disadvantage of needing a new lower deck with suitable standoff structures to support the main cargo deck and its load above the solar arrays. The team did not spend much time developing feasible designs for a lower deck and the required standoff structures. Figures 13 and 14 show a basic saw-tooth grid pattern as one possible solution for the standoff structure. In fact, the solar arrays could possibly attach to the underside of the cargo deck, avoiding a second deck altogether.

Figure 13 shows how the solar arrays could slide out from the lower deck, and Fig. 14 shows how they could swing out. Although swinging the arrays out is probably easier to implement, the slide-out approach preserves more of the support structure for the upper cargo deck.

\section{Structural Analysis}

This section provides a preliminary assessment of the primary structural design drivers for horizontally deployed Mars surface solar arrays. These arrays are different than spacecraft solar arrays because of the large array area requirement coupled with environmental conditions such as gravity, wind loads, and dust accumulation. Because of the severe launch vehicle volume constraints and the large area required, only thin stretched solar cell blanket arrays are considered. First, the effects of Mars gravity and wind forces on blanket loads and deflections are presented. Second, mass trends are presented of the structure required to withstand the Mars gravity and wind loads. Results include blanket loads, blanket deflections, fundamental vibration frequencies, and mass trends.

\section{A. Blanket Loads, Deflections, and Frequency}

Figure 15 shows the analysis assumptions and blanket sag that results from the gravity load. To provide efficient solar energy collection and adequate ground clearance, the blanket sag must be kept small. For small deflections, the kinematic analysis presented in Fig. 16 provides adequate accuracy for preliminary design. ${ }^{24}$

Figure 17 presents the analysis results. The baseline solar array blanket length is $22.5 \mathrm{~m}$, but the effective blanket length for sag calculations is just $11.25 \mathrm{~m}$ if a mid-length support leg is used that also supports the blanket. For a blanket sag of $0.5 \mathrm{~m}$, the axial end displacement is just $0.05 \mathrm{~m}$ (2") for the $11.25 \mathrm{~m}$ long blanket. Thus, if a constant force spring provides the blanket tension, it needs a 2" stroke. For a $22.5 \mathrm{~m}$ long blanket without the mid-length support leg, the spring stroke with $0.5 \mathrm{~m}$ sag reduces to $0.025 \mathrm{~m}$ (1"), although the applied tension load increases by a factor of 4 . These axial deflection and tension values are required for designing the spring system to determine its feasibility. 
To calculate the tension required to support the blanket subjected to gravity or wind loads, it is necessary to determine the effective pressure on the blanket induced by these two conditions. The assumed values of the necessary parameters are:

- Blanket mass/area, $\mathrm{q} \sim 0.5-1 \mathrm{~kg} / \mathrm{m}^{2}$

- $\quad$ Blanket tension*, $\mathrm{N}_{\mathrm{b}} \sim 70-280 \mathrm{~N} / \mathrm{m}$

- Mars atmospheric density $\sim 0.010-0.020 \mathrm{~kg} / \mathrm{m}^{3}$

- Wind velocity $\sim 0-50 \mathrm{~m} / \mathrm{s}(0-112 \mathrm{mph})$

- Drag Coefficient, $\mathrm{C}_{\mathrm{D}}=1$

*The ISS solar array blanket tension is $~ 70 \mathrm{~N} / \mathrm{m} .{ }^{25}$

The blanket mass per unit area for Mars surface arrays is assumed to be in the range of 0.5 to $1.0 \mathrm{~kg} / \mathrm{m}^{2}$. The range of blanket tension/width considered is assumed to be between 70 to $280 \mathrm{~N} / \mathrm{m}$. The lower value of tension matches that of the ISS solar arrays while the upper value was chosen to be four times the ISS solar array tension.

Figure 18 shows the resulting blanket sag as a function of blanket length for a tension level of $280 \mathrm{~N} / \mathrm{m}$. The blue dot on the figure shows that the maximum sag for a $22.5 \mathrm{~m}$ long blanket is less than $0.5 \mathrm{~m}$ for $\mathrm{q}=0.5 \mathrm{~kg} / \mathrm{m}^{2}$ and is double that value for $\mathrm{q}=1 \mathrm{~kg} / \mathrm{m}^{2}$. This sag is shown drawn to scale in the upper sketch of Fig. 19. Although this value of sag appears acceptable from an operational point of view, the required tension of $280 \mathrm{~N} / \mathrm{m}$ may be too high for practical design of constant force springs. Providing a cross support at the halfway point of the blanket reduces the tension required to maintain a $0.5 \mathrm{~m}$ maximum sag to $70 \mathrm{~N} / \mathrm{m}$. This is the same tension used for the space station solar arrays. ${ }^{25}$ Also shown in Fig. 19 are the associated blanket natural frequencies. In both cases the frequency is $0.52 \mathrm{~Hz}$. This is a relatively low frequency, and the system should be studied further to determine whether expected wind loads would induce an undesirable dynamic excitation.

The effective pressure exerted on the blanket by a wind normal to the blanket is presented in Fig. 20 as a function of wind velocity and atmospheric density. Although wind normal to the blanket is a worst-case situation, this conservative assumption should be used until more is understood about wind directions including those from dust devils. For comparison, the effective gravitational pressures exerted by two values of blanket mass per unit area are also shown. As can be seen in the figure, the effective wind pressure will exceed the effective gravitational pressure for the expected blanket mass per unit area of $0.5 \mathrm{~kg} / \mathrm{m}^{2}$ at a wind velocity of only $12 \mathrm{~m} / \mathrm{s}$ with an atmospheric density of $0.020 \mathrm{~kg} / \mathrm{m}^{3}$. Such low values of wind velocity may result in the blanket exhibiting uncontrolled oscillations. Recommendations based on Computational Fluid Dynamics (CFD) and scale-model wind tunnel tests should determine if additional stiffening is required.

The major observations of this study are:

- Gravity blanket sag values appear acceptable for reasonable values of blanket tension.

- However, associated blanket vibration frequencies are low enough to be of concern. CFD and wind tunnel studies should be conducted to determine if aerodynamic excitation is an issue.

- Potential wind loads are high enough that consideration should be given to development of wind-load alleviation concepts.

The first observation is that reasonable values of blanket tension result in acceptable values of blanket sag from ground clearance and solar collection efficiency considerations. However, these tension levels result in low blanket natural frequencies that should be studied for potential aerodynamic excitations. Lastly, there are no obvious simple solutions for dealing with variable-direction high wind loads. Maximum wind speeds exceeding $40 \mathrm{~m} / \mathrm{s}$ can produce pressures on the blanket that greatly exceed the stabilizing pressure exerted by gravity. This situation may lead to 
undesirable blanket deformations or motion. A solution is to develop blankets with patches that open to provide load alleviation under high wind loadings. In some wind conditions, it may be desirable to adjust the solar array tilt angle to minimize aerodynamic (or aeroelastic) loads, rather than to maximize output power.

\section{B. Mass Trends for Mars Surface Arrays}

The major assumptions used for solar array mass trend studies are:

- 1 Earth g loading is major design requirement implemented to account for Mars wind loadings.

- Array blanket mass $/ \mathrm{area}=1 \mathrm{~kg} / \mathrm{m}^{2}$.

- Structural mass investigated for the following parameters:

- Value of g loading

- Wing support conditions

- Assumed packaging volume

- Packaging volume is a design variable constraint to be traded at the system level.

- Current study aimed at providing major trends for guiding concept studies.

Although Mars gravity is only 0.38 times the value of Earth gravity, consideration has been given to use the value of Earth gravity for preliminary design purposes. Using the value of Earth gravity in design has been proposed to account for unknown Mars wind conditions and enable development testing on Earth. In this section, array mass was investigated for $1 \mathrm{~g}$ and $0.5 \mathrm{~g}$ to provide insight into the impact of this assumption. Also investigated was the effect of wing support conditions and the effect of changing array package volume on array mass. Although array packaging volume is a major mass driver, the volume must be evaluated at a system level as lander packaging studies are conducted. The emphasis of the current study was to provide major array mass trends that can assist in future array concept developments and integration of the array with the lander.

The dimensions of the array are defined in Fig. 21, where L and B are the length and width of the array blanket and $\mathrm{h}$ and $\mathrm{b}$ are the dimensions of the telescoping boom members. The number of telescoping members is considered to be the number of members within the blanket length, $\mathrm{L}$.

Figure 22 shows the total mass of a cantilevered CTSA wing as a function of wing length for two values of assumed gravity loading, where parameter " $\mathrm{a}$ " is the ratio of gravitational loading to Earth gravity. The lower blue line is the mass of the blanket only. As can be seen from the curves, the impact of the value of gravity becomes increasingly important for wing lengths greater than 15 meters. A major driver for these curves was the assumed value of array packaging volume of $3 \mathrm{~m}^{3}$. The reason the volume has such a large impact on the structural mass was that it controls the cross-sectional size of the telescoping members.

Next, Figure 23 shows the total mass of the array wing for two boundary support conditions; namely, the array was assumed to be cantilevered from the lander, and the array was assumed to be supported at the tip. As can be seen in the figure, the mass for an array with a tip support was significantly lower than the mass for a cantilevered array. This tip support can be achieved by dropping a support leg to the ground, or by a guy support cable provided from the lander.

Finally, Figure 24 shows the total mass of the array for three values of assumed stowed volume. Although the structural mass decreases with increases in volume, an integrated lander package will be required to assess the proper weighting to be assigned to this mass decrease.

Further details of the $100 \mathrm{~m}^{2}$ array design shown by the black dot on the last three figures are shown in Fig. 25 . Here, the array cross section appears quite small on a $10 \mathrm{~m}$ diameter lander. Although it would seem that increasing volume to decrease array mass would be a good trade, the best value of the packaging volume is not well understood. 
The major observations of this preliminary Mars surface array mass study are:

- $1 \mathrm{~g}$ design feasible for a cantilevered $100 \mathrm{~m}^{2}$ CTSA wing for which structural mass is approximately equal to array mass.

- Structural mass sensitive to major design drivers:

- Wing gravity loading

- Array support conditions

- Packaging volume

- Current mass studies aimed at providing major trends to guide concept development; however, significant additional detailed design, development, and verification required.

- Further aerodynamic studies required to determine if $1 \mathrm{~g}$ loading is an adequate design requirement.

It was shown that a cantilevered $100 \mathrm{~m}^{2}$ array subjected to a $1 \mathrm{~g}$ loading was feasible for a structural mass approximately equal to the blanket mass. Further studies showed that this structural mass would be reduced significantly by reducing the gravitational loading, providing an array tip support, or by increasing allowable array packaging volume. It should be emphasized that the current study was preliminary, and that considerable additional detailed design, development, and verification is required. Of major concern was the assumption of a $1 \mathrm{~g}$ loading to account for poorly understood wind conditions. A strong recommendation is to conduct early CFD analyses and scalemodel wind tunnel tests to help understand and quantify the effects of Mars winds on large tensioned-blanket solar arrays.

\section{Technology Gaps and Additional Trade Studies}

At the end of this study, the team identified three major technology gaps and several remaining trade studies needed to mature lightweight, large-area solar arrays for Mars surface power.

The main technology gaps are:

- Mid-TRL structures and mechanism technologies for large-area, flexible blanket solar arrays.

- Exceptionally compact packaging and integration with Mars lander

- Structural/mechanical design, analysis, and test of 1-g and 3/8-g deployment, 1-g deployment off loading, blanket sag management

- Mars surface deployed structure performance under gravity loads and Martian wind loading

- Mars near surface (0-5 m altitude) wind velocity profiles over the period of at least one Martian year for probable landing sites, including a major dust storm and a dust devil, if possible.

- Dust abatement/removal technology.

- Demonstrate high effectiveness (>90\% dust clearing) on flexible blanket solar arrays with ground chamber simulations

- Demonstrate in-situ experiments on Mars surface operating for at least one Martian year at probable landing sites

Eight additional trade studies needed in future studies are:

- Rotating the entire solar array wing vs. rotating individual blankets vs. extending legs unequal amounts to rotate the wing.

- Using continuous blankets vs. including gaps in blankets to shed dust and reduce wind loads.

- Deploying the blankets with the boom (synchronous deployment) vs. hoisting them after the boom is fully deployed (sequential deployment).

- Using a 3-sided vs. 4-sided telescoping boom.

- Using a jack-screw vs. bi-STEM vs. rack-and-pinion boom deployer. 
- Using transverse blanket supports vs. higher blanket tension to minimize blanket sagging in the Mars $0.38 \mathrm{~g}$ gravity.

- Using one vs. multiple locations for array rotation motors.

- Using an internal vs. external boom actuator.

This list is not all-encompassing but contains topics the team identified in this preliminary study.

\section{Conclusions}

Based on the preliminary design and analysis reported in this paper, the Compact Telescoping Surface Array appears to be a feasible approach for large, lightweight Mars solar arrays that autonomously deploy from Mars landers on initial human exploration missions. The $1000 \mathrm{~m}^{2}$ CTSA arrays were shown to produce at least $10 \mathrm{~kW}$ of day/night continuous power at low- and mid-latitude landing sites when coupled with regenerative fuel cells for energy storage to supply power at night and during dust storms. The paper focused on the structural and mechanical aspects of the solar array and presented three feasible variations of the CTSA concept. This study did not include any prototype hardware construction and testing, so for now the designs covered in the paper are mostly low-TRL conceptual ideas only. Successful development of these ideas are within reach and should lead to the desired capabilities for large-scale solar power generation on Mars.

\section{Acknowledgments}

The CTSA was developed during the Solar Arrays with Storage (SAWS) seedling study funded by the NASA STMD Game Changing Development (GCD) Program in fiscal year 2017. The authors acknowledge the support of Mr. Chuck Taylor (LaRC), the previous STMD Principal Technologist for Power and Energy Storage who conceived the SAWS study, and his successor STMD Principal Technologist, Mr. Lee Mason (GRC), who continues to provide strong support for this technology development leading to eventual comparison with other power solutions. The authors also acknowledge help from the SAWS solar power experts at GRC: Tom Kerslake, Jeremiah McNatt, Mike Piszczor, and Geoff Landis, as well as the seedling study Project Manager, Fred Elliott, who is also at GRC. Expert advice on Mars surface mission plans from Michelle Rucker (JSC) and regenerative fuel cells from Koorosh Araghi (JSC) and Ian Jakupca (GRC) is also gratefully acknowledged.

\section{References}

${ }^{1}$ Mason, L., "Kilopower: Small Fission Power Systems for Mars and Beyond," Future In-Space Operations (FISO) telecon seminar with recorded audio, February 1, 2017, http://fiso.spiritastro.net/telecon/Mason_2-1-17/.

${ }^{2}$ Cataldo, R., "Power Requirements for NASA Mars Design Reference Architecture (DRA) 5.0," Presented at the 3rd Topical Meeting on Nuclear and Emerging Technologies for Space, June 2009.

${ }^{3}$ NASA Space Technology Mission Directorate website, “Advanced Solar Array Systems,” October 31, 2012, https://www.nasa.gov/offices/oct/home/feature_sas.html.

${ }^{4}$ Mason, L., "Status of NASA Space Technology Mission Directorate Investments in Space Power," Presented at the 35th Space Power Workshop, April 2017.

${ }^{5}$ Rucker, M. et al., "Solar vs. Fission Surface Power for Mars," AIAA Paper 2016-5452, Presented at the AIAA Space Forum, September 2016.

${ }^{6}$ Mason, L., "How We Can Achieve Humans on Mars by the 2030s, A Surface Power Perspective," Presented at the Humans to Mars Summit, May 2017.

${ }^{7}$ Rucker, M., "Human Mars Mission Power Architectures," Presented at the 35th Space Power Workshop, April 2017.

${ }^{8}$ Pappa, R. and Kerslake, T., "Mars Surface Solar Arrays," Future In-Space Operations (FISO) telecon seminar with recorded audio, June 7, 2017, http://fiso.spiritastro.net/telecon/Pappa-Kerslake_6-7-17/.

${ }^{9}$ Kerslake, T. and Kohout, L., "Solar Electric Power System Analyses for Mars Surface Missions,” NASA/TM-1999-209288, July 1999. 
${ }^{10}$ Haberle, R. et al., "Atmospheric Effects on the Utility of Solar Power on Mars," Resources of Near-Earth Space, University of Arizona Press, 1993, pp. 845-885.

${ }^{11}$ Kerslake, T., "Mars Surface Solar Power Systems," Panel on Planetary Surface Power at the AIAA Propulsion and Energy Forum, July 2017, https://livestream.com/AIAAvideo/PropEnergy2017/videos/159709334.

${ }^{12}$ Landis, G. and Appelbaum, J., "Photovoltaic Power System Operation on Mars," paper AAS 90-247, Presented at the 4th Case for Mars Conference, June 1990.

${ }^{13}$ McKissock, B. and Kohout, L., “A Solar Power System for an Early Mars Expedition,” NASA TM-103219, August 1990.

${ }^{14}$ Colozza, A., Appelbaum, J., and Crutchik, M., “A Photovoltaic Catenary-Tent Array for the Martian Surface,” NASA CR191144, May 1993.

${ }^{15}$ McNatt, J., Landis, G., and Fincannon, J., "Design of Photovoltaic Power System for a Precursor Mission for Human Exploration of Mars," Presented at the 43rd IEEE Photovoltaic Specialists Conference, June 2016.

${ }^{16}$ Mikulas, M., Pappa, R., Warren, J., and Rose, G., "Telescoping Solar Array Concept for Achieving High Packaging Efficiency," AIAA Paper 2015-1398, Presented at the AIAA SciTech Forum, January 2015.

${ }^{17}$ Subtopic H5.01 on "Mars Surface Solar Array Structures," https://sbir.nasa.gov/printpdf/58384, in the NASA SBIR 2017 Phase I Solicitation.

${ }^{18}$ McEachen, M., "Compact Telescoping Array: Advancement from Concept to Reality," Presented at the AIAA SciTech Forum, January 2018.

${ }^{19}$ Petri, D., Cataldo, R., and Bozek, J., "Power System Requirements and Definition For Lunar and Mars Outposts," Presented at the 25th Intersociety Energy Conversion Engineering Conference, August 1990.

${ }^{20}$ Anonymous, “Single Axis Trackers," https://en.wikipedia.org/wiki/Solar_tracker\#Single_axis_trackers, On-line Wikipedia article.

${ }^{21}$ Huybrechts, S., "Method for Making Advanced Grid-Stiffened Structures,” U.S. Patent 6,245,274, June 2001.

${ }^{22}$ Gurley, A., “The Design of Optimal Lattice Structures Manufactured by Maypole Braiding,” Journal of Mechanical Design, October 2015.

${ }^{23}$ Pappa, R., Rose, G., Chamberlain, M., Paddock, D., and Mikulas, M., “Mars Surface Solar Array Structures,” Presented at the 35th Space Power Workshop, April 2017.

${ }^{24}$ Murphey, T., Murphy, D., Mikulas, M., and Adler, A., “A Method to Quantify the Thrust Degradation Effects of Structural Wrinkles in Solar Sails," AIAA Paper 2002-1560, Presented at the 43rd AIAA Structures, Dynamics, and Materials Conference, April 2002.

${ }^{25}$ Johnson, M, Haugen, B., and Anderson, G., "Space Station Freedom Solar Array Containment Box Mechanisms," Presented at the 28th Aerospace Mechanisms Symposium, May 1994. 
Table 1. Solar Array Design Guidelines.

\begin{tabular}{|c|c|}
\hline 1 & Autonomous deployment from lander. \\
\hline 2 & Solar arrays must self deploy. No prepositioned robotic assistants available. \\
\hline 3 & Assume no lander azimuth control. (Might change.) \\
\hline 4 & $\begin{array}{l}\text { No firm mission power requirements yet. Assume solar array area and } \\
\text { calculate electrical power at various landing sites. OK for tech development. }\end{array}$ \\
\hline 5 & $1000 \mathrm{~m}^{2}$ area per lander. Provides a "10 kW-class" solar power system. \\
\hline 6 & Extensible to $1500+\mathrm{m}^{2}$ area per lander for higher latitudes and dustier skies. \\
\hline 7 & $\begin{array}{l}\text { Mass goal }<1.5 \mathrm{~kg} / \mathrm{m}^{2} \text { inc. all mechanical and electrical; } 1.5 \mathrm{mt} \text { for } 1000 \mathrm{~m}^{2} \text {. } \\
\text { Assume lightweight blanket mass of } 0.5 \mathrm{~kg} / \mathrm{m}^{2} \text {. }\end{array}$ \\
\hline 8 & Total stowed volume $<10 \mathrm{~m}^{3}$, which is $\sim 30 \mathrm{~kW} / \mathrm{m}^{3}$ at $1 \mathrm{AU}$. \\
\hline 9 & $\begin{array}{l}\text { Solar array deploys in Mars } 0.38 \mathrm{~g} \text { gravity \& low winds (use } 0.5 \mathrm{~g} \text { total for } \\
\text { preliminary design). }\end{array}$ \\
\hline 10 & $\begin{array}{l}\text { Deployable on terrain with up to } 0.5-\mathrm{m} \text { rocks, } 15 \text { deg slopes, and potentially } \\
\text { hidden hazards (e.g., sand-filled holes). }\end{array}$ \\
\hline 11 & $\begin{array}{l}\text { Should deploy high enough to avoid sand collection but as low as possible to } \\
\text { minimize wind loads. }\end{array}$ \\
\hline 12 & Time to deploy: $8 \mathrm{hr}$ max. \\
\hline 13 & $\begin{array}{l}\text { Solar array operates in Mars } 0.38 \mathrm{~g} \text { gravity \& wind gusts (use } 1.0 \mathrm{~g} \text { total for } \\
\text { preliminary design). }\end{array}$ \\
\hline 14 & $\begin{array}{l}\text { Must survive } 120 \text { days of } 40 \mathrm{~m} / \mathrm{sec} \text { wind gusts in storms and } 100 \mathrm{~m} / \mathrm{sec} \text { peak } \\
\text { winds (dust devil), which "feel like" } \sim 30 \mathrm{mph} \text { Earth winds. }\end{array}$ \\
\hline 15 & Solar array must not tip over or twist excessively in high winds. \\
\hline 16 & Ability to tilt arrays for dust removal and to feather in high winds. \\
\hline 17 & Probably also need vibration, electrostatics, jets, or wipers to remove dust. \\
\hline 18 & Evaluate cost/benefits of being retractable, relocatable, and reconfigurable. \\
\hline 19 & $\begin{array}{l}\text { Compare } 29.5 \% \mathrm{XTJ} / \mathrm{ZTJ} \text {, near-term } 34 \% \text { IMM4J, and far-term } 37 \% \text { IMM6] } \\
\text { solar cells. Nominal solar array operating voltage is } 120 \mathrm{~V} \text {. }\end{array}$ \\
\hline 20 & $\begin{array}{l}\text { Must survive daily temperature change of } \sim 120 \mathrm{C} \text { (approx. }-100 \mathrm{C} \text { to } 20 \mathrm{C} \\
\text { near equator) over a lifetime }>10 \text { years. }\end{array}$ \\
\hline
\end{tabular}




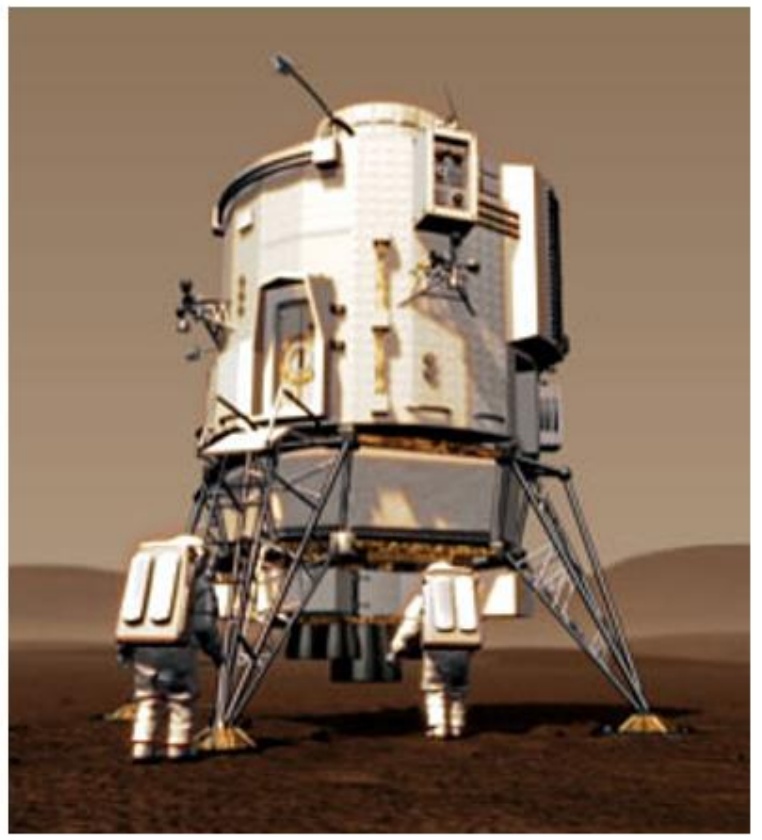

(a) Vertical Lander

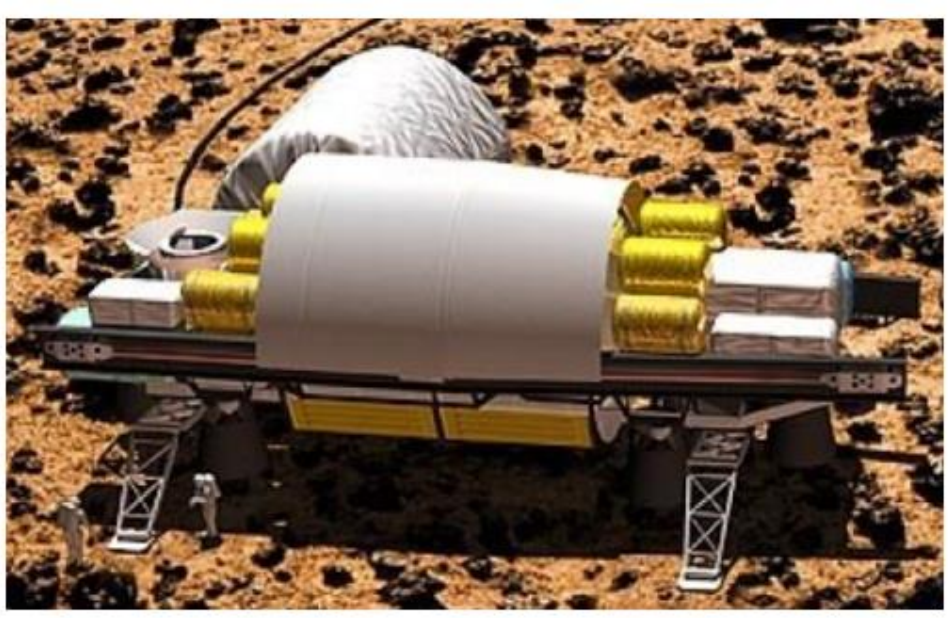

(b) Horizontal Lander

Figure 1. Mars Lander Concepts.

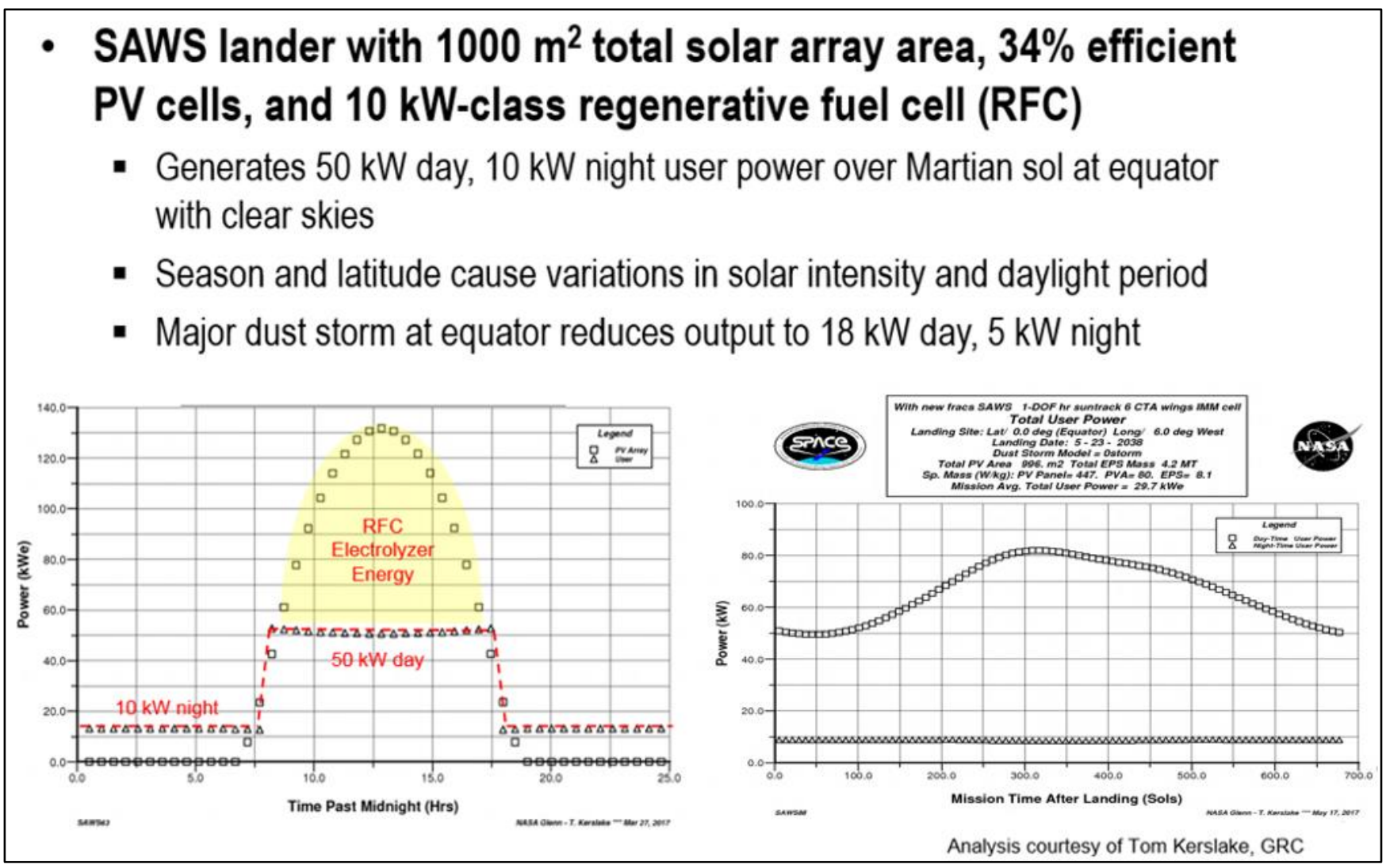

Figure 2. Power Predictions at Mars Equator. 


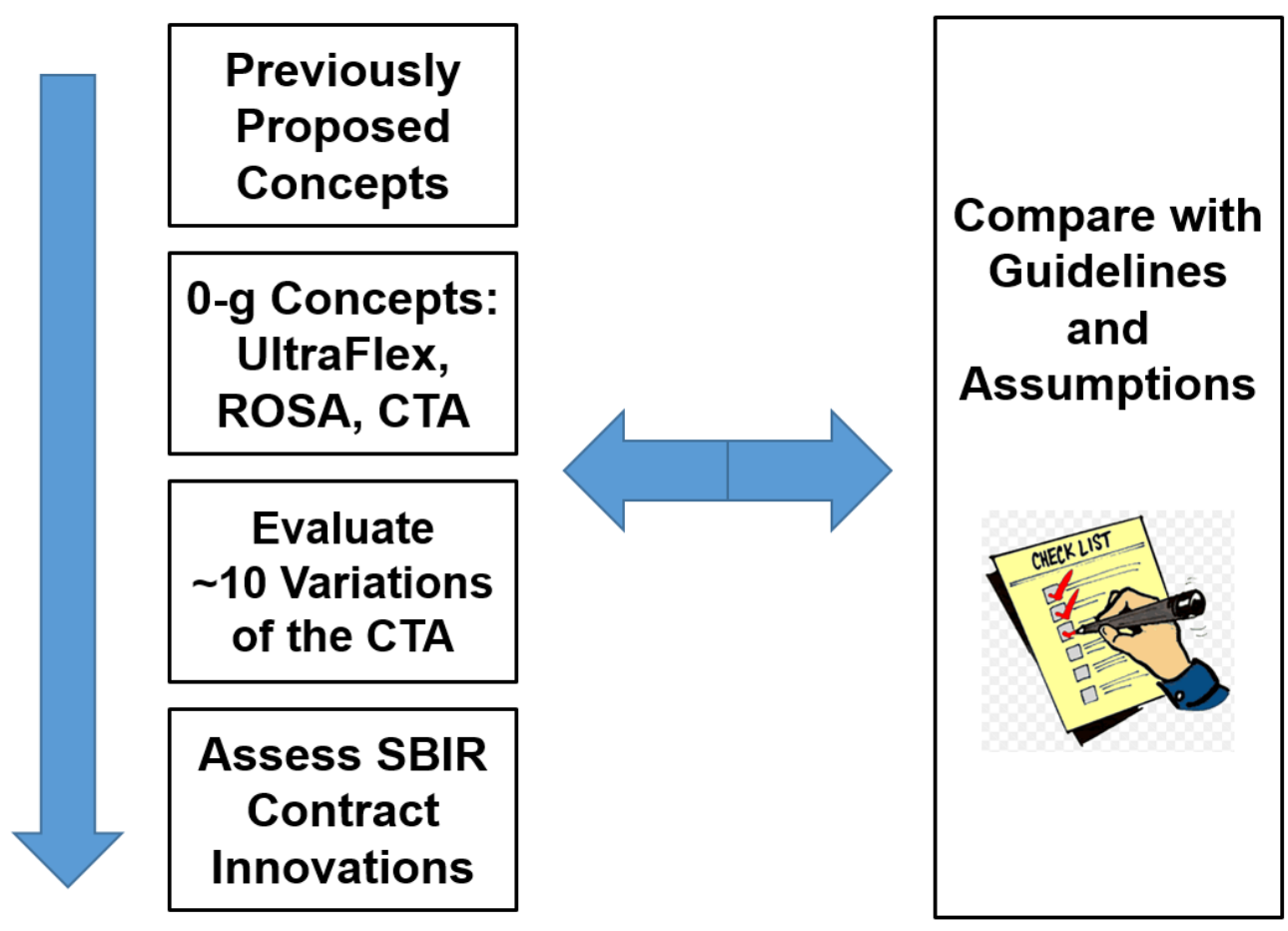

Figure 3. Solar Array Concept Selection.

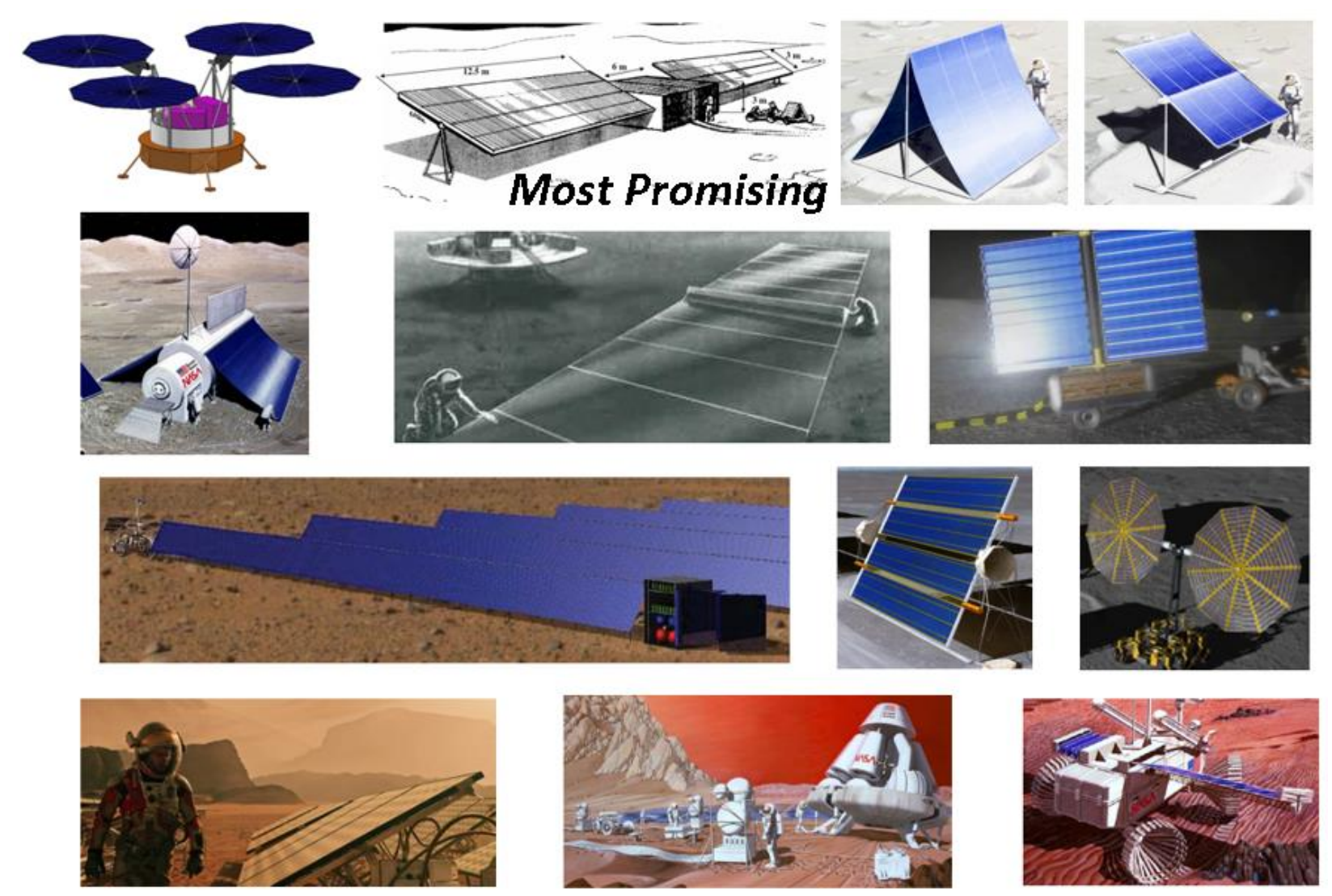

Figure 4. Some Previously Proposed Solar Array Concepts. 


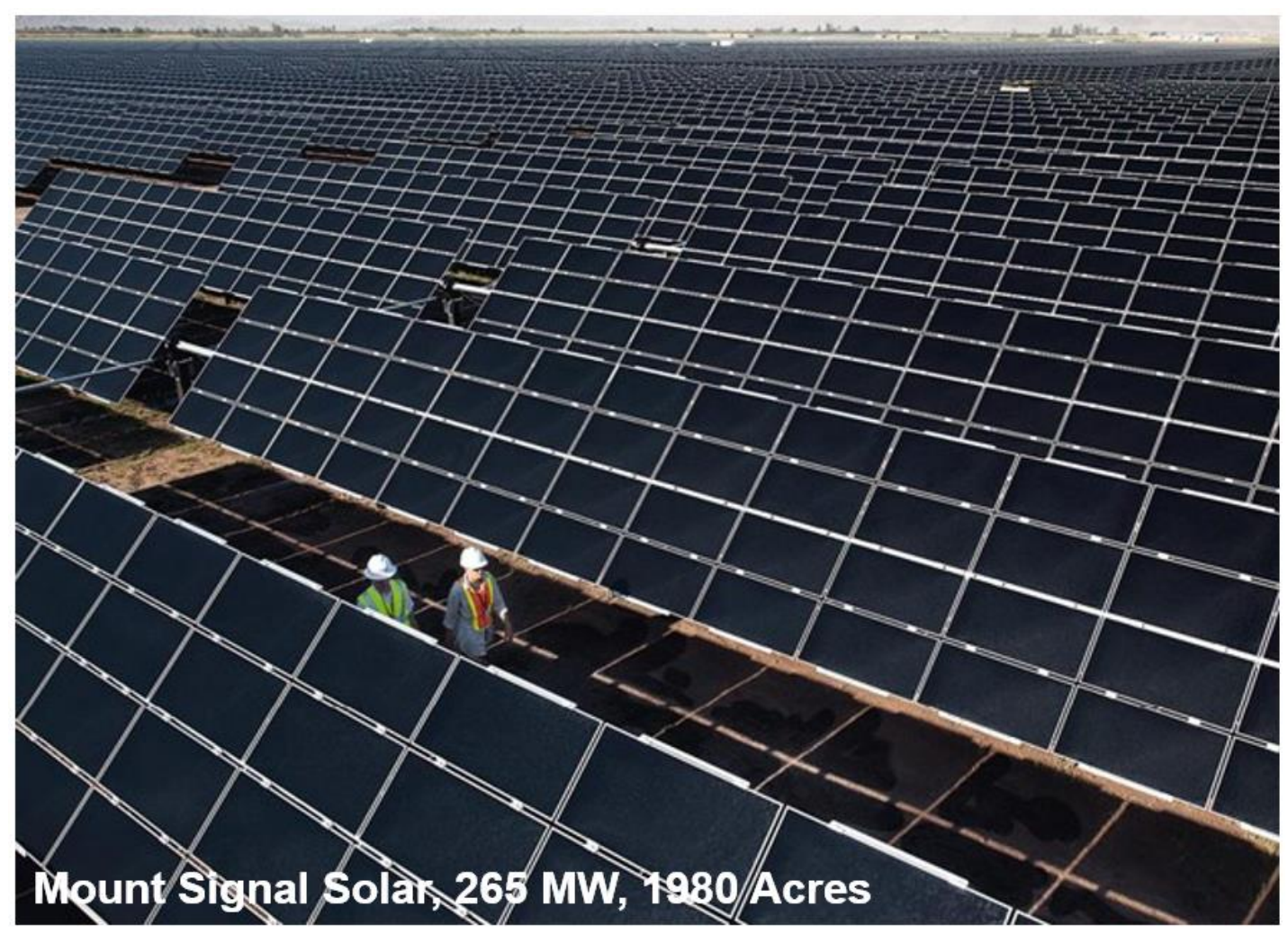

Figure 5. Large Terrestrial Solar Arrays Were Also Reviewed.

1

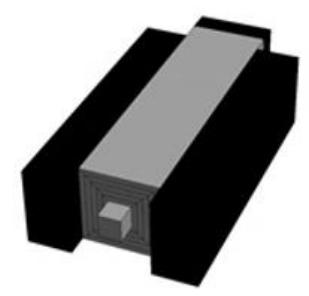

3

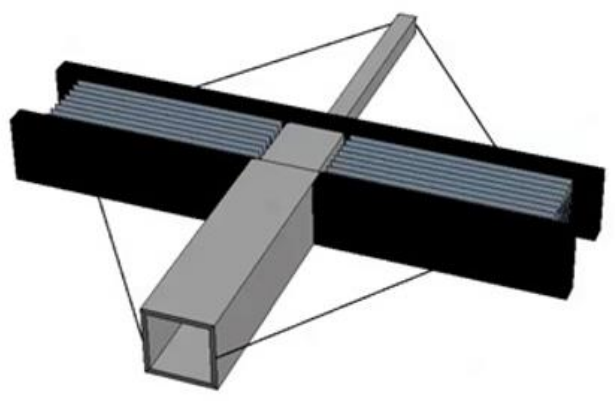

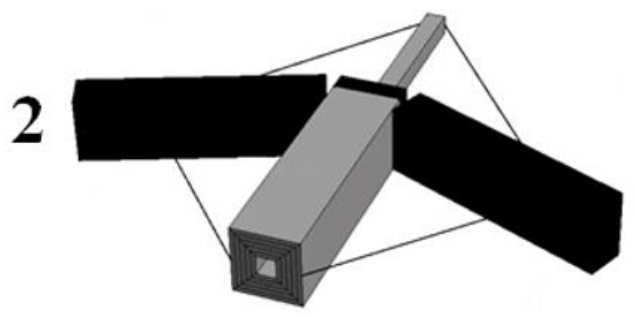

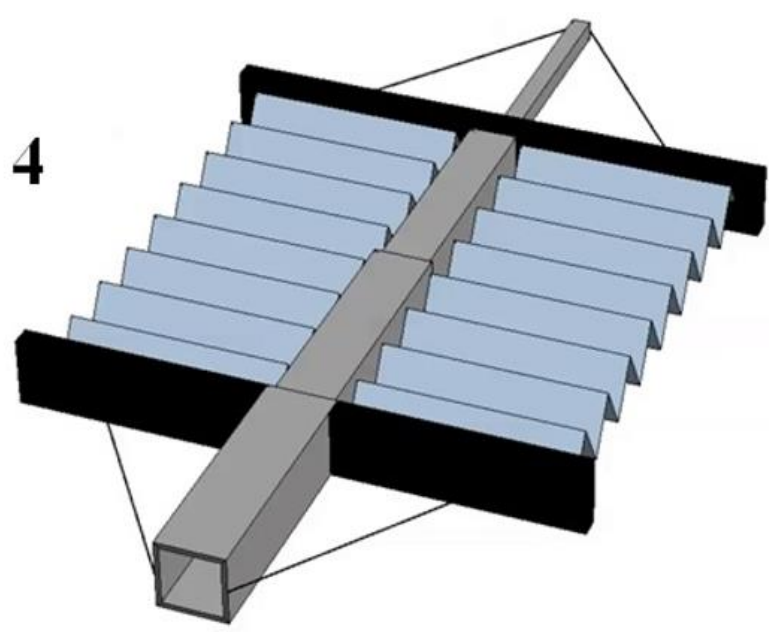

Figure 6. LaRC's Compact Telescoping Array (CTA) Conceptual Deployment. 


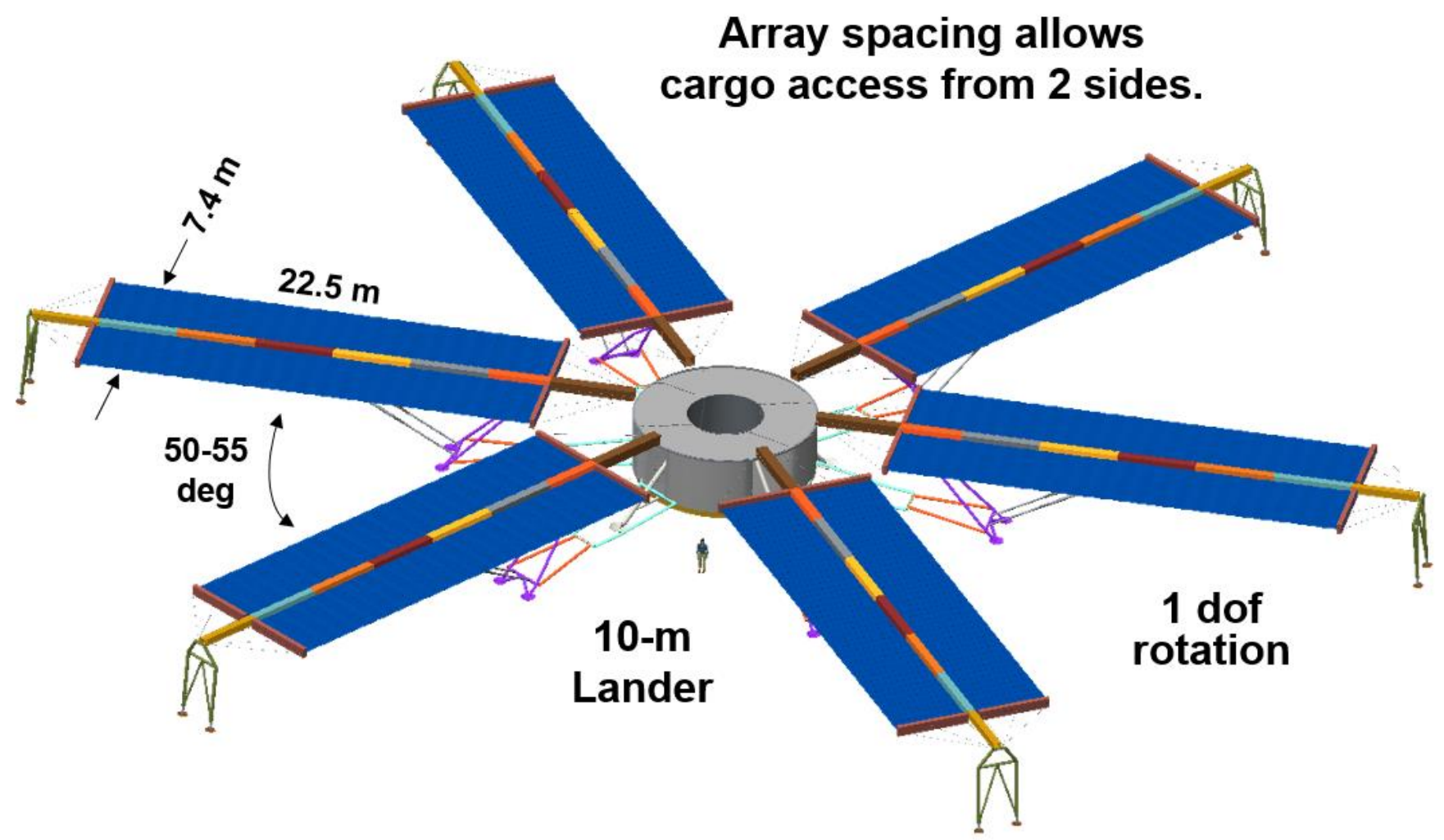

Figure 7. Baseline $1000 \mathrm{~m}^{2}$ Design Using Six CTA Solar Array Wings.
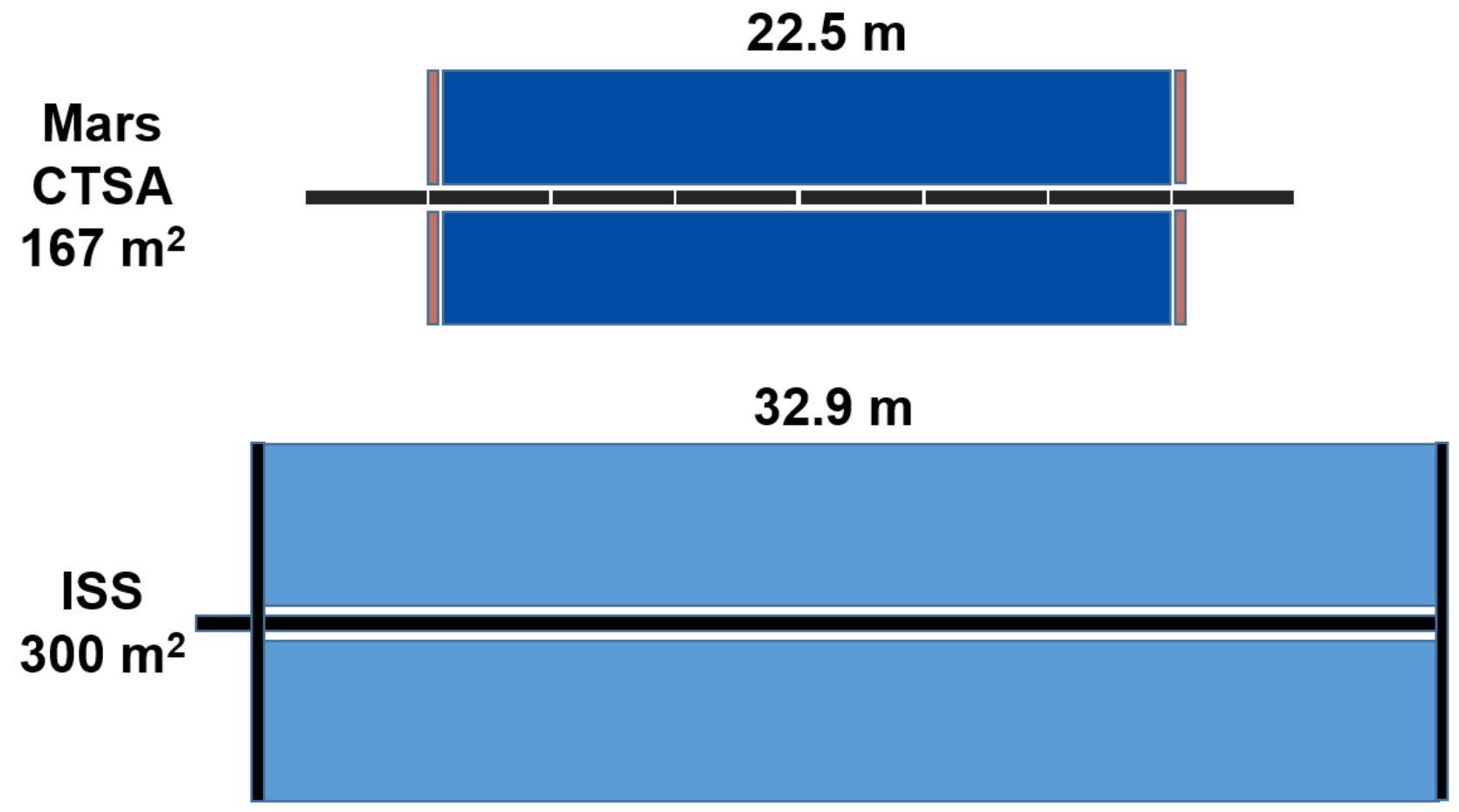

Figure 8. Size Comparison with ISS Solar Array Wing. 

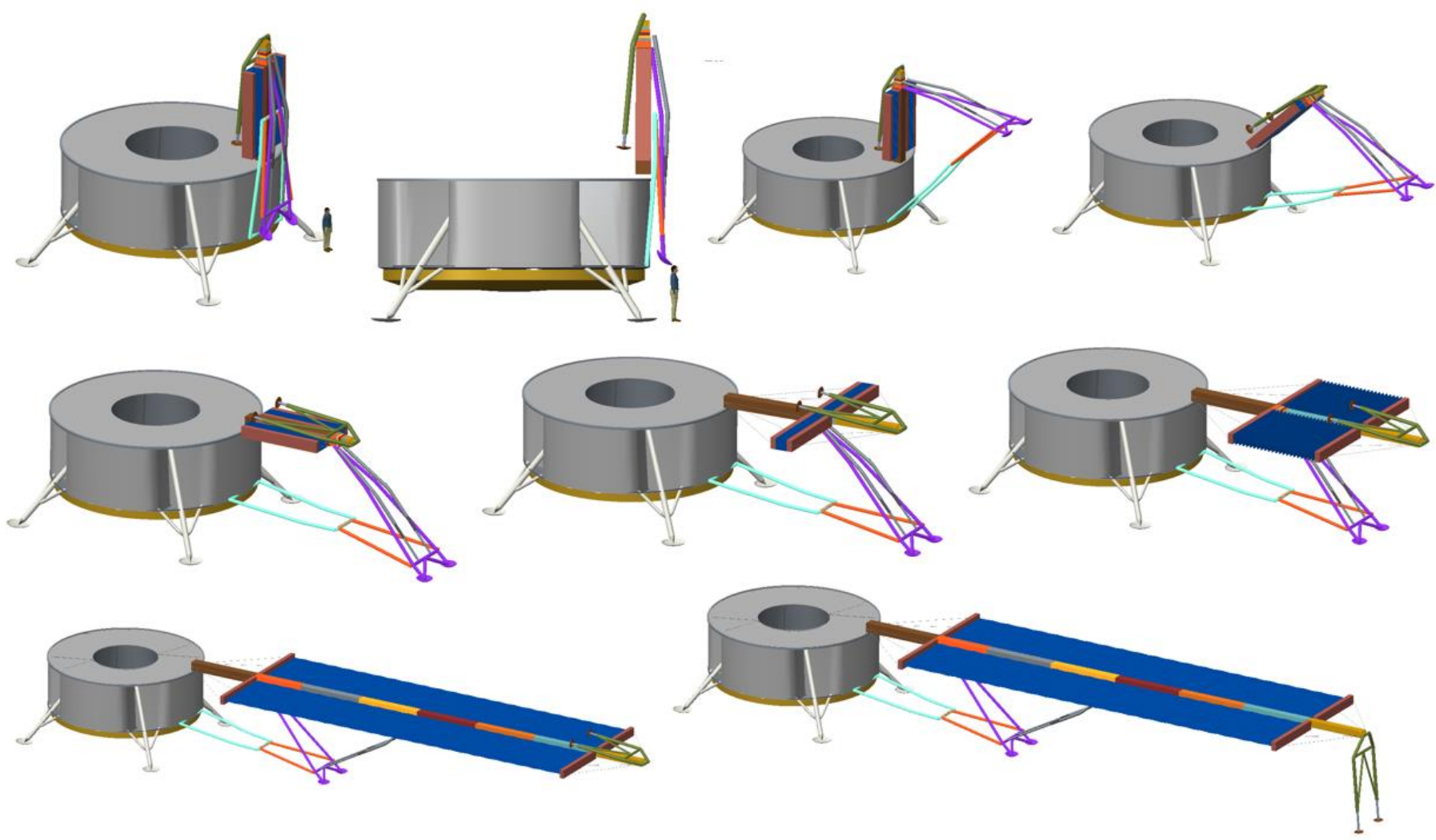

Figure 9. Baseline Solar Array Conceptual Deployment.
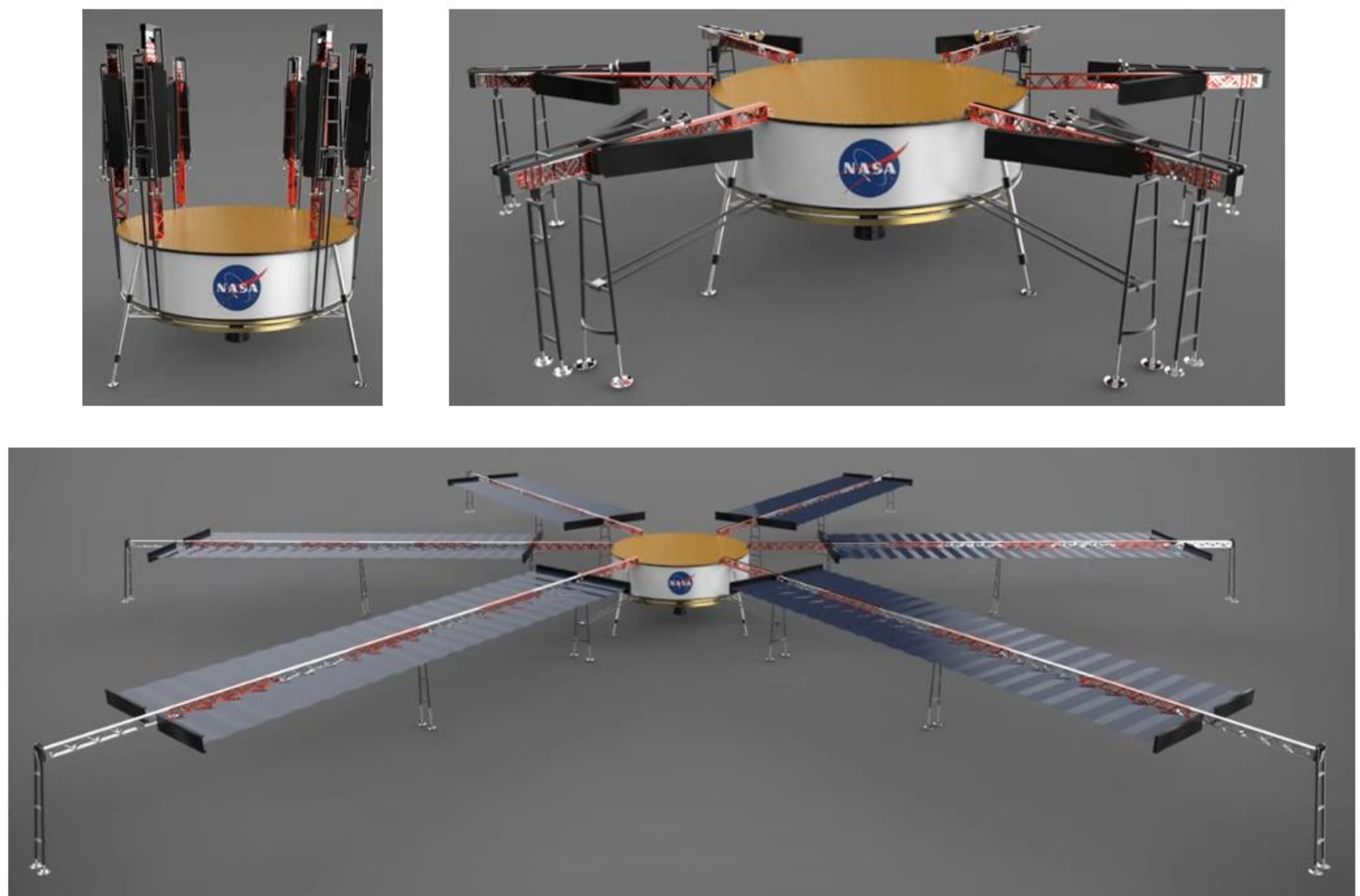

Figure 10. High-Fidelity Rendering of Baseline Solar Array Concept. 


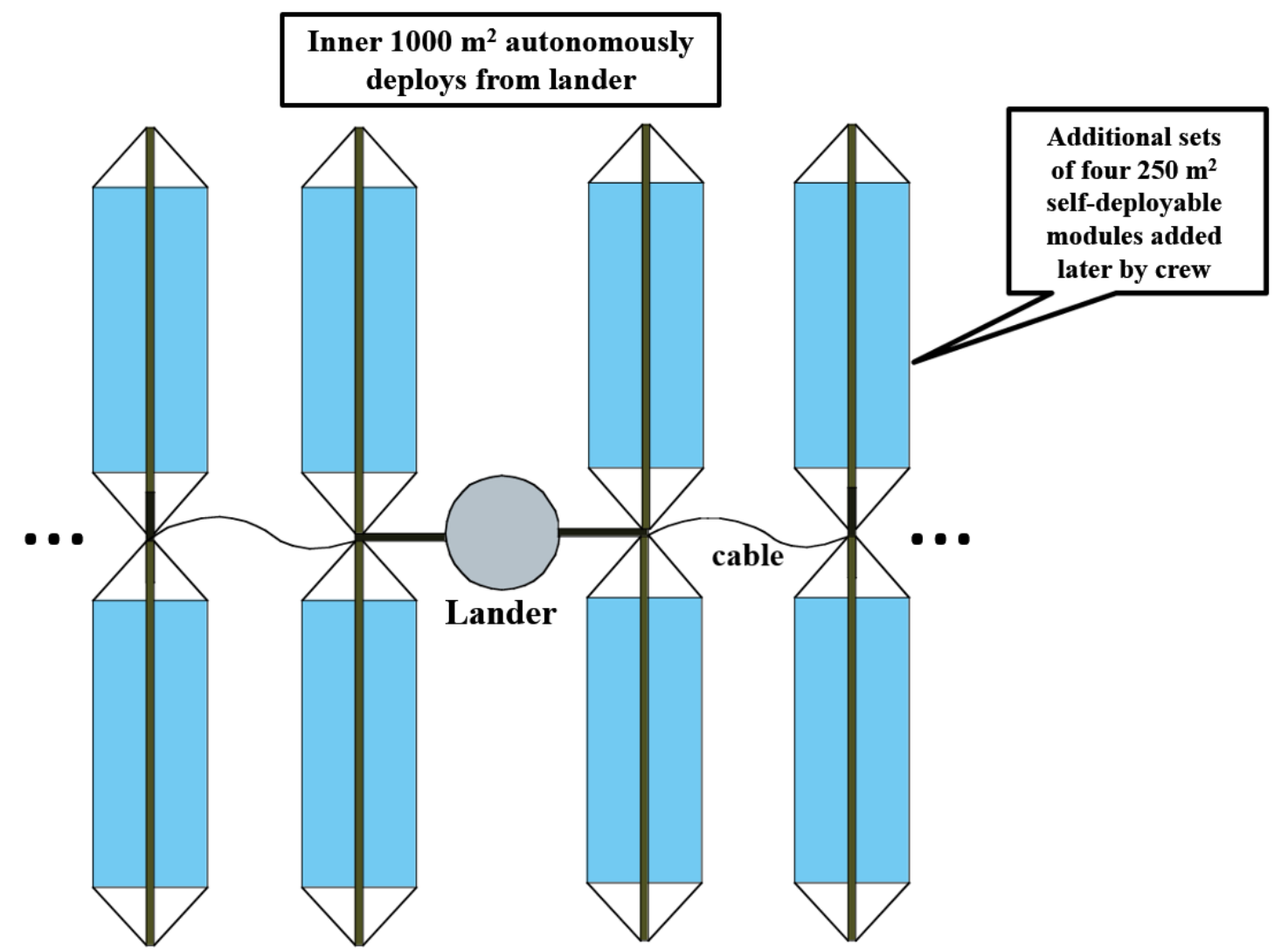

Figure 11. Alternative Solar Array Configuration for Expanding to $2000+\mathbf{m}^{2}$ of Area.
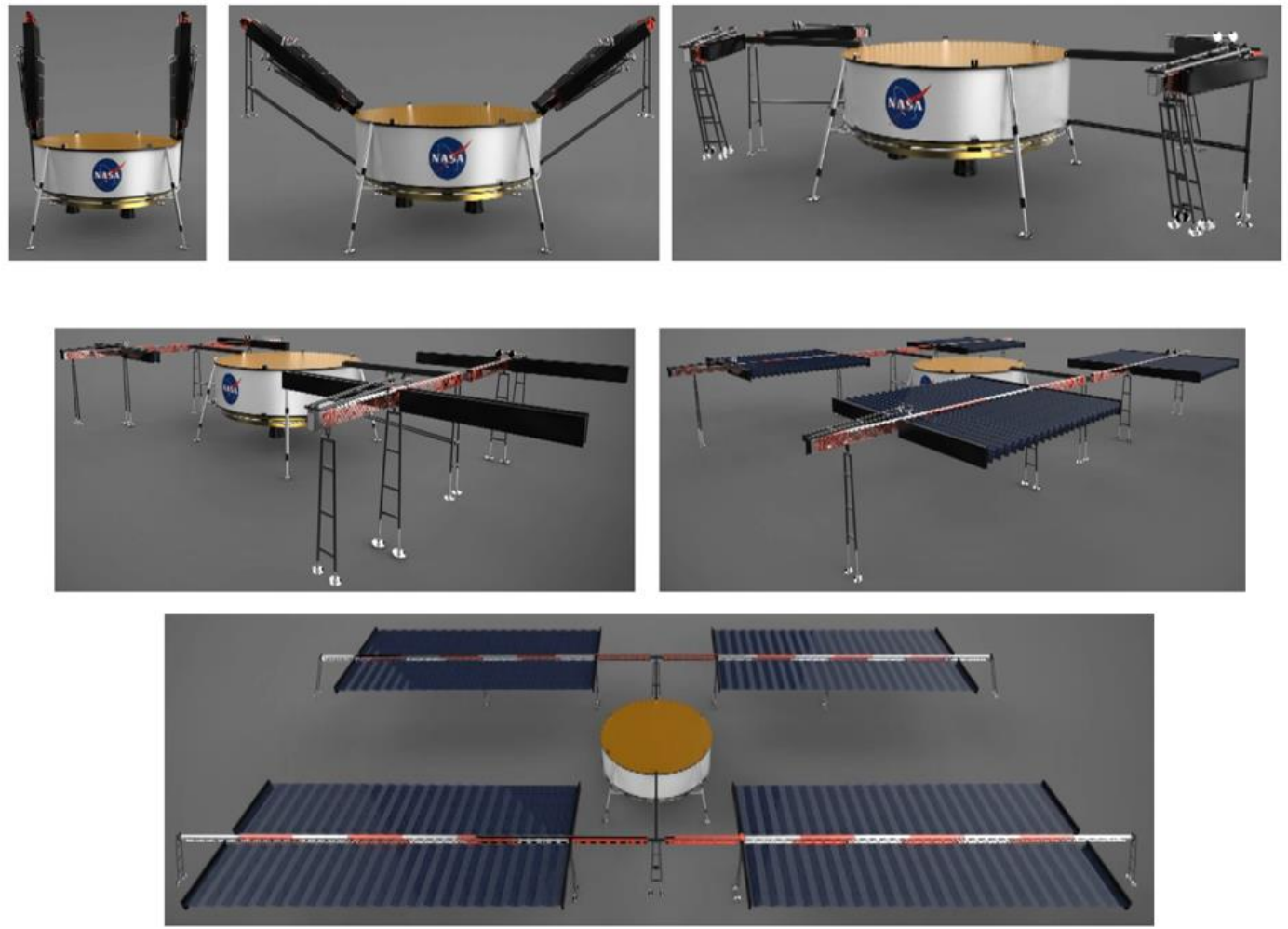

Figure 12. High-Fidelity Rendering of H-Configuration Solar Array. 

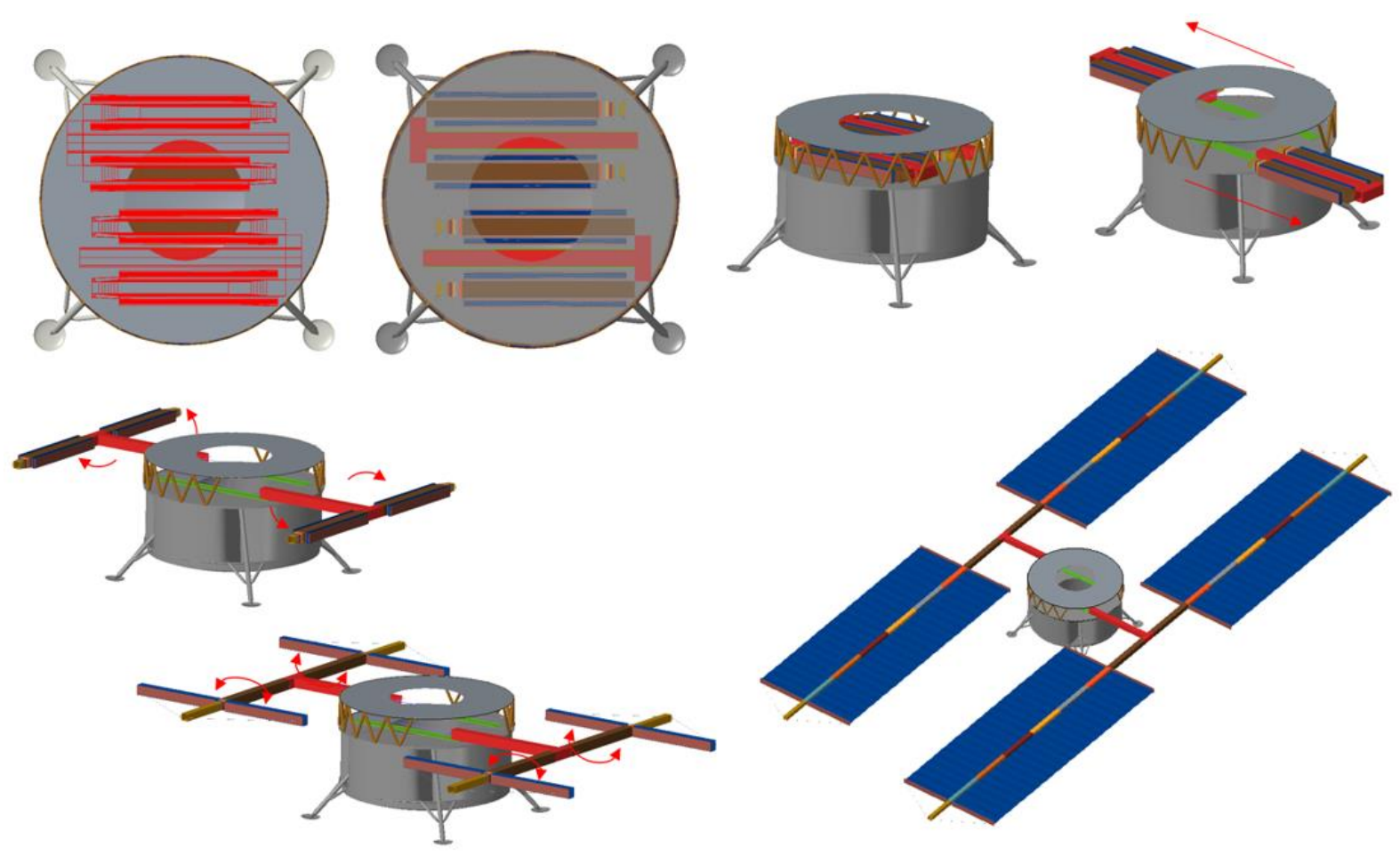

Figure 13. Slide-Out Concept that Stows Below the Cargo Deck.
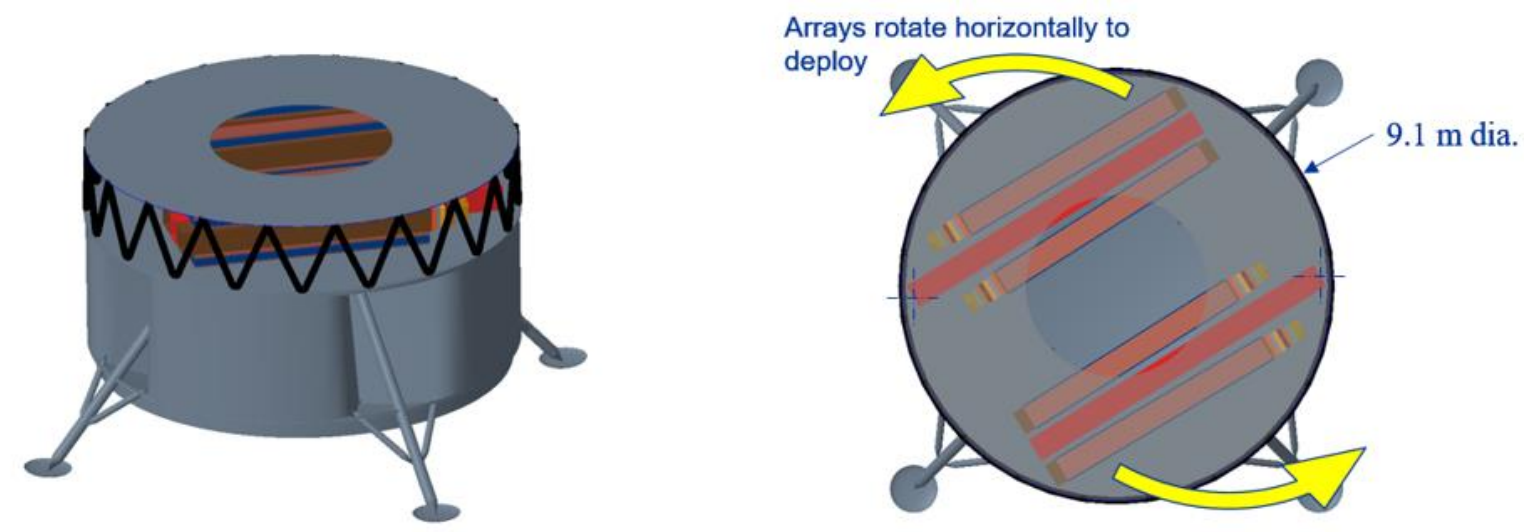

- Shown stowed under top deck, with primary cargo above

- Could be incorporated as permanent part of Mars landers

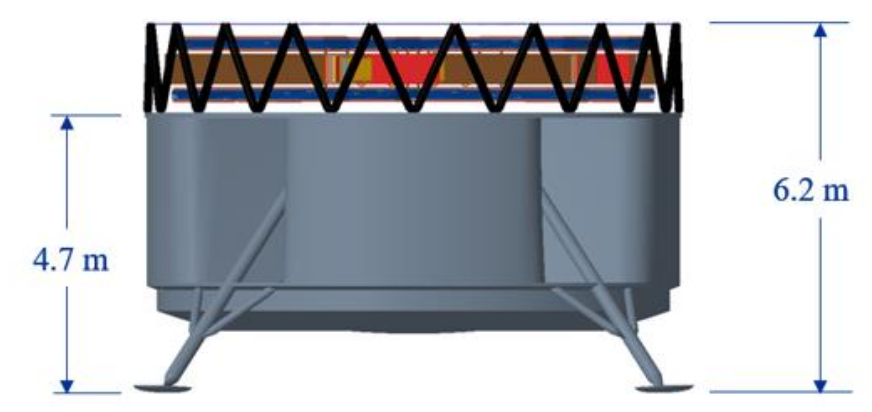

Figure 14. Swing-Out Concept that Stows Below the Cargo Deck. 
A constant axial force (value not included in kinematic analysis) supports blanket The sag is approximated by a small deflection sinusoidal shape

Blanket does not stretch

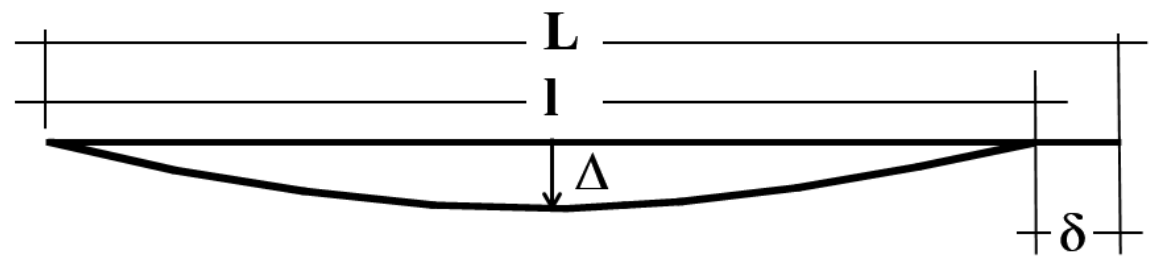

This study shows how much axial displacement is required as a function of sag. This is required for axial spring design.

Note that axial spring could be incorporated into the telescoping structure

A subsequent analysis will quantify the value of axial load required as a function of the sag, $\Delta$

Allowing additional sag will provide load relief from large wind loads

The subsequent analysis will also present blanket frequency

Figure 15. Blanket Kinematic Analysis Assumptions.

Assume wrinkles with a sinusoidal profile given by,

$$
\mathbf{a}=\Delta y=a \sin \left(\pi \frac{x}{l}\right),
$$

where $a$ is the wrinkle amplitude and $l$ is the length of one half cycle of wrinkle projected on the $x$ axis

The total length of the wrinkle $(L)$ is given exactly by Reference 24 as,

$$
L=\int_{0}^{l} \sqrt{1+\left(\frac{d y}{d x}\right)^{2}} d x .
$$

$$
\begin{aligned}
& d s^{2}=d x^{2}+d y^{2} \\
& \text { or } \\
& s=\int_{0}^{l}\left(1+\left(\frac{d y}{d x}\right)^{2}\right) d x
\end{aligned}
$$

Symbolic evaluation of this equation requires the inconvenience of elliptic integrals. For this paper, relatively small wrinkles $(a / l<0.2)$ are assumed so that the approximate form of shortening due to the profile, given by,

$$
\delta=L-l=\frac{1}{2} \int_{0}^{l}\left(\frac{d y}{d x}\right)^{2} d x=\frac{\pi^{2}}{4} \frac{a^{2}}{l},
$$

or

is valid (less than $7 \%$ error up to $a / l<0.2$,

For an array blanket with a sag, $\Delta$, the axial shortening, $\delta$, is given by this result, where $a=\Delta$.

Figure 16. Kinematic Analysis of Axial Deflection and Blanket Sag. 


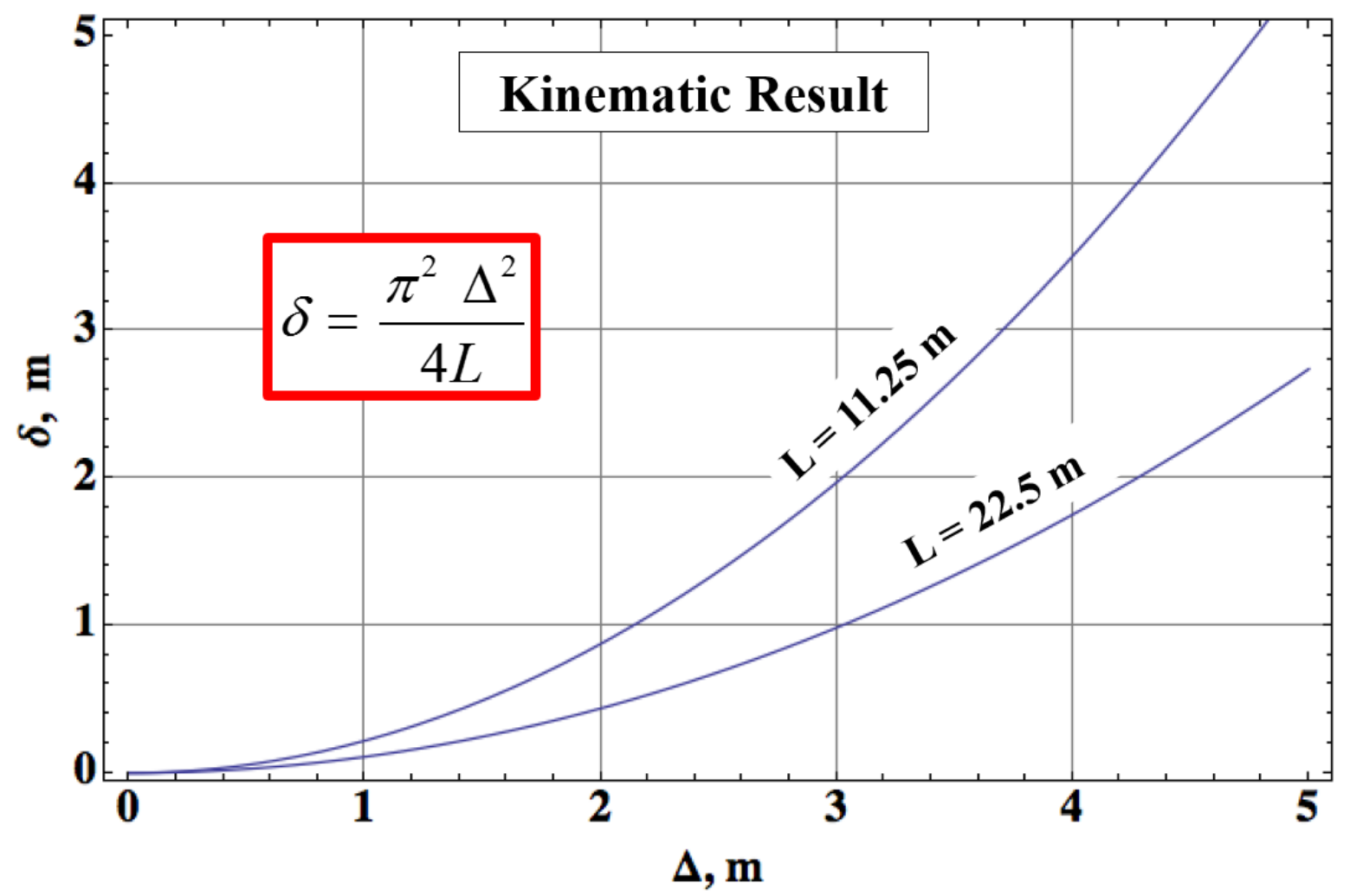

Figure 17. Blanket Axial Deflection, $\delta$, Due to a Sag, $\Delta$.

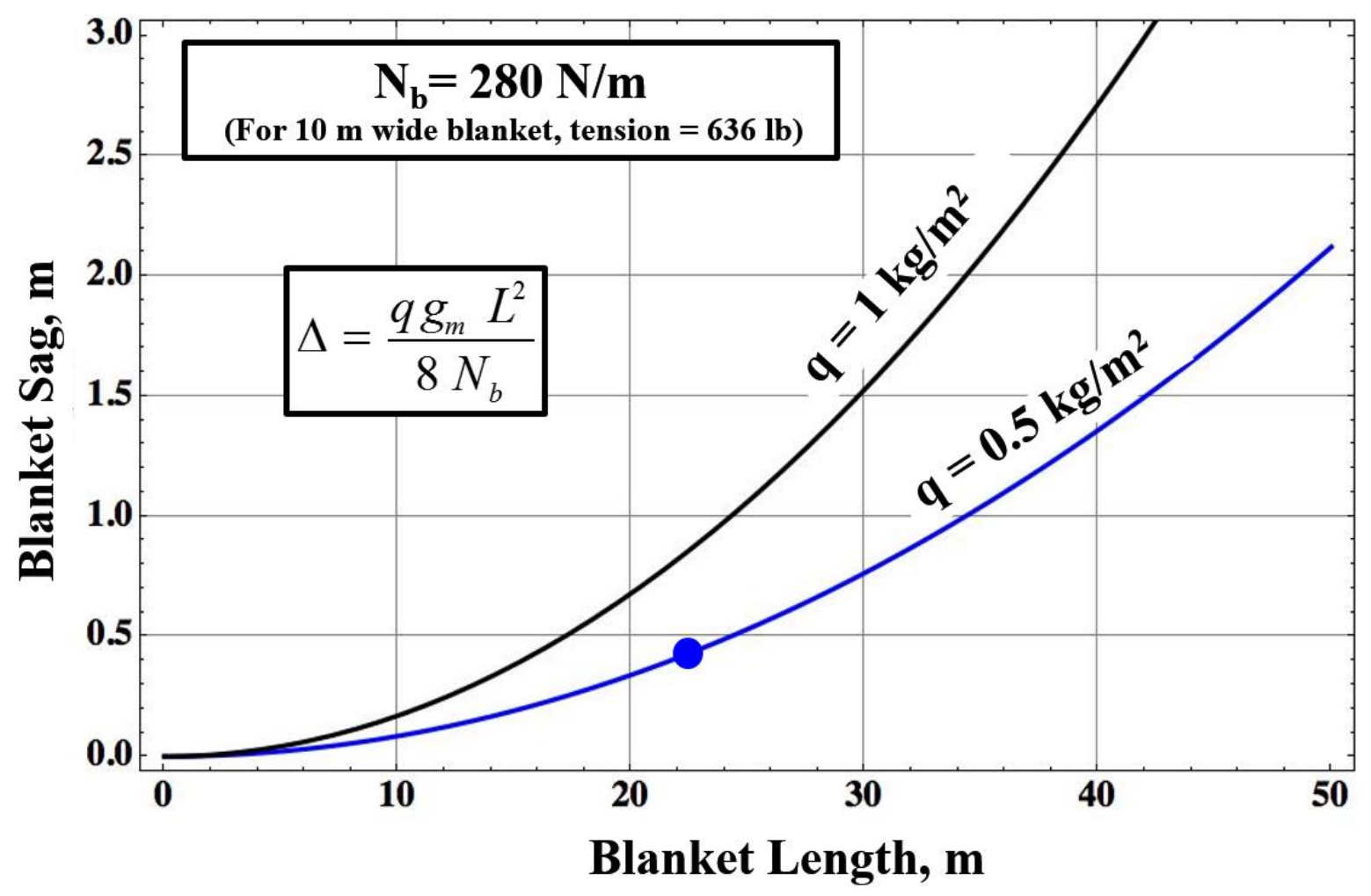

Figure 18. Blanket Sag Versus Blanket Length and Mass per Unit Area. 


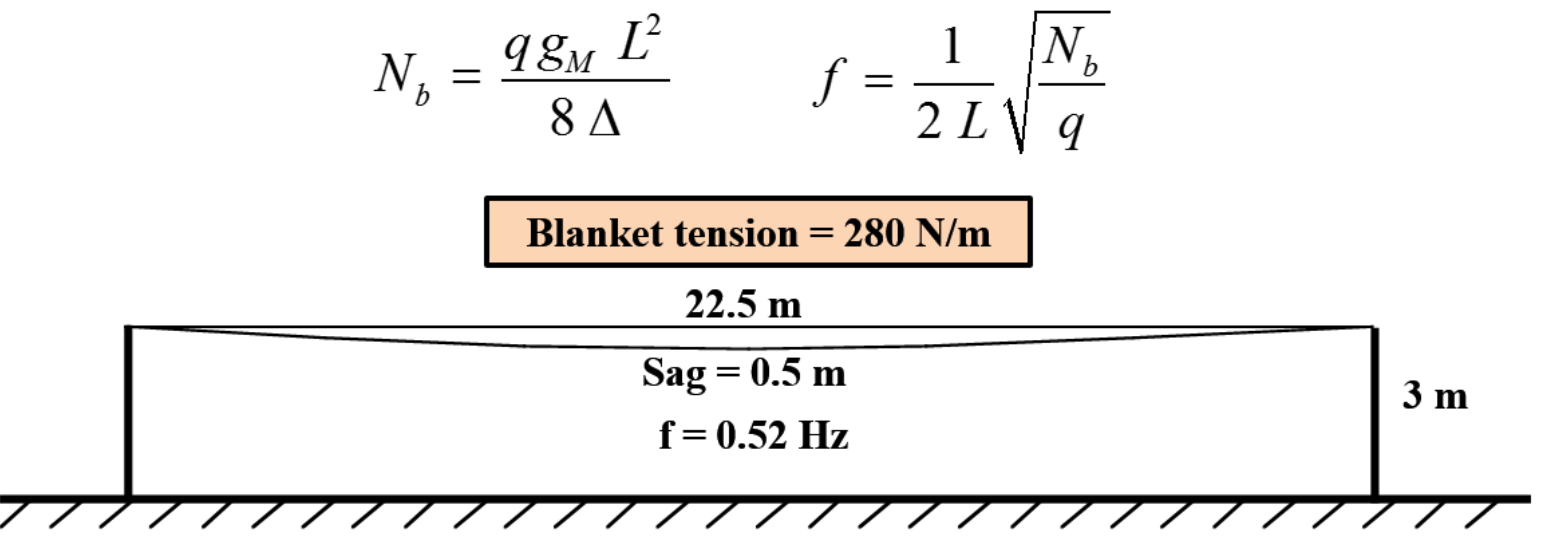

Add Blanket Center Support

\section{Blanket tension $=70 \mathrm{~N} / \mathrm{m}$}

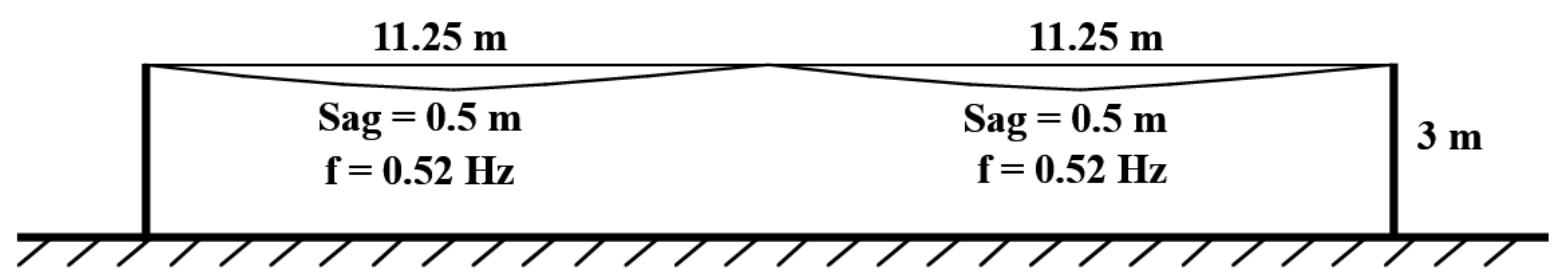

Figure 19. Blanket Sag and Required Blanket Tension for Two Support Conditions.

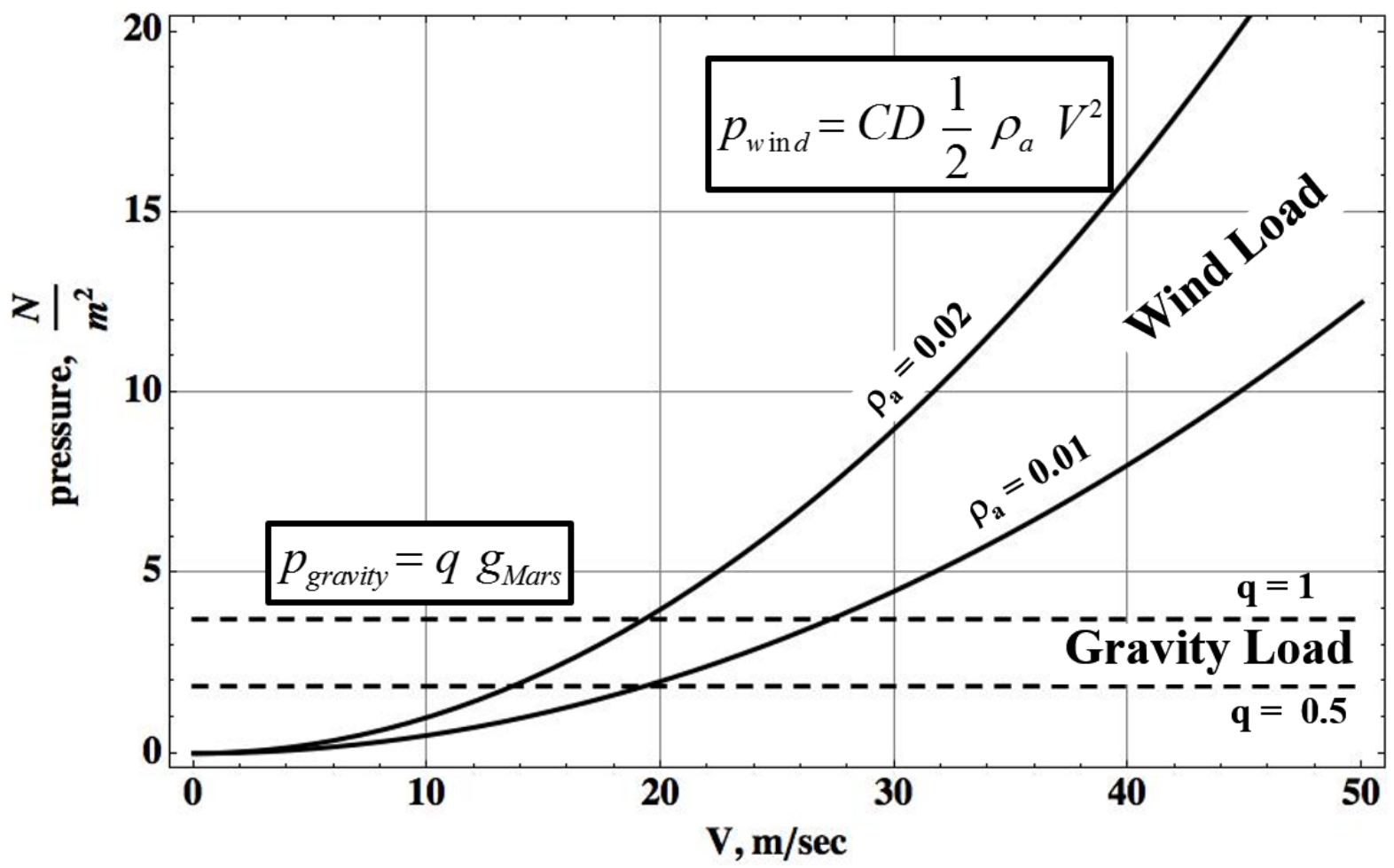

Figure 20. Effective Wind Pressure Acting on Blanket Versus Wind Velocity. 


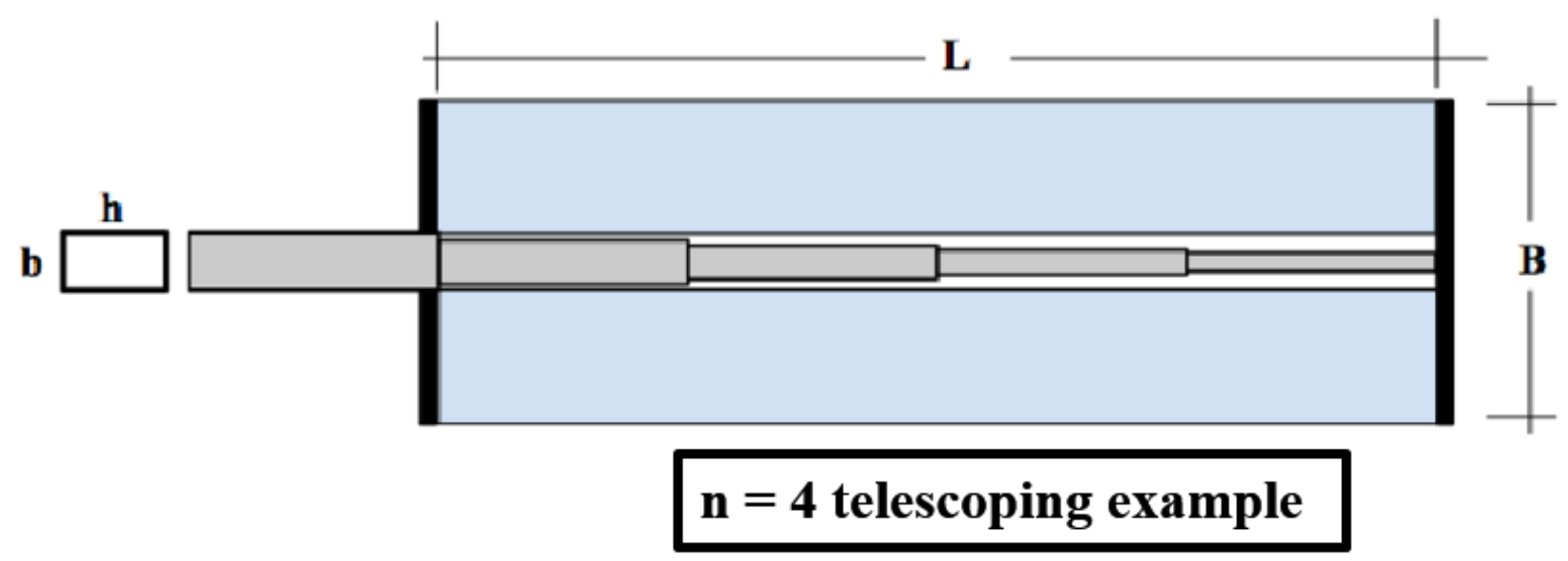

Figure 21. Schematic and Dimensions of the CTSA.

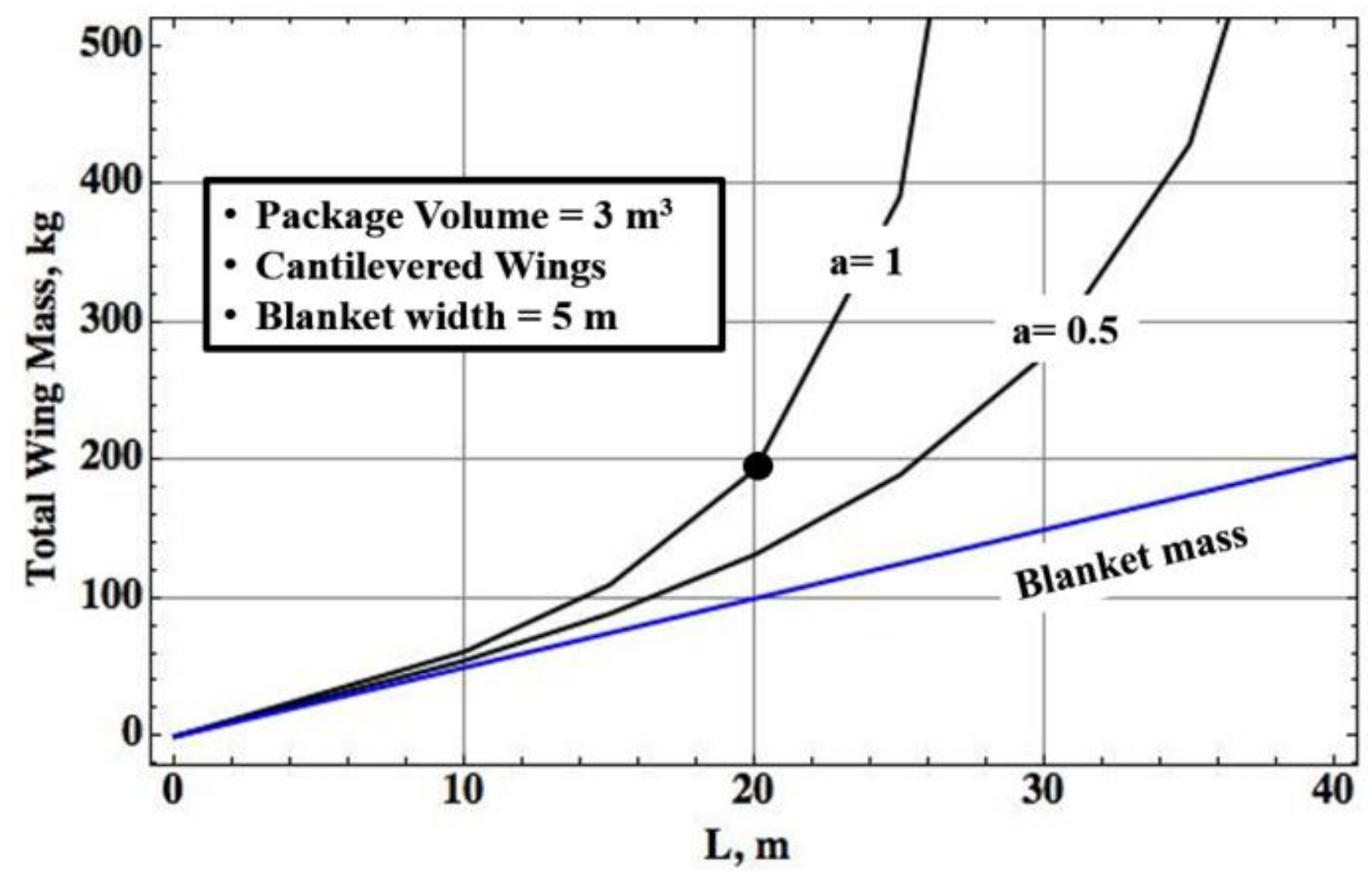

Figure 22. CTSA Structural Mass Versus Wing Length, L, and g Loading Factor, a. 


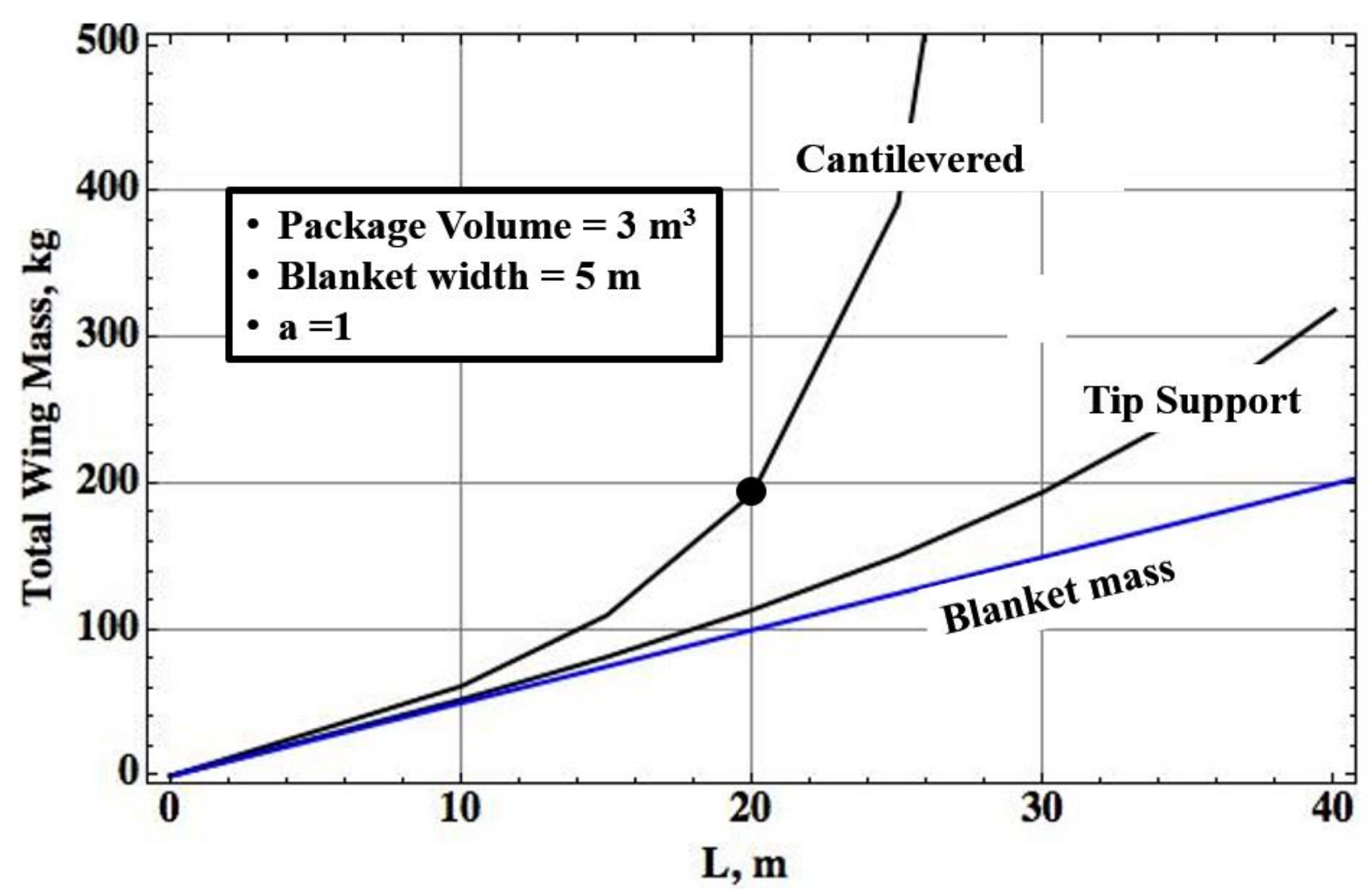

Figure 23. A Tip Support for the Array Provides Major Reduction in Structural Mass.

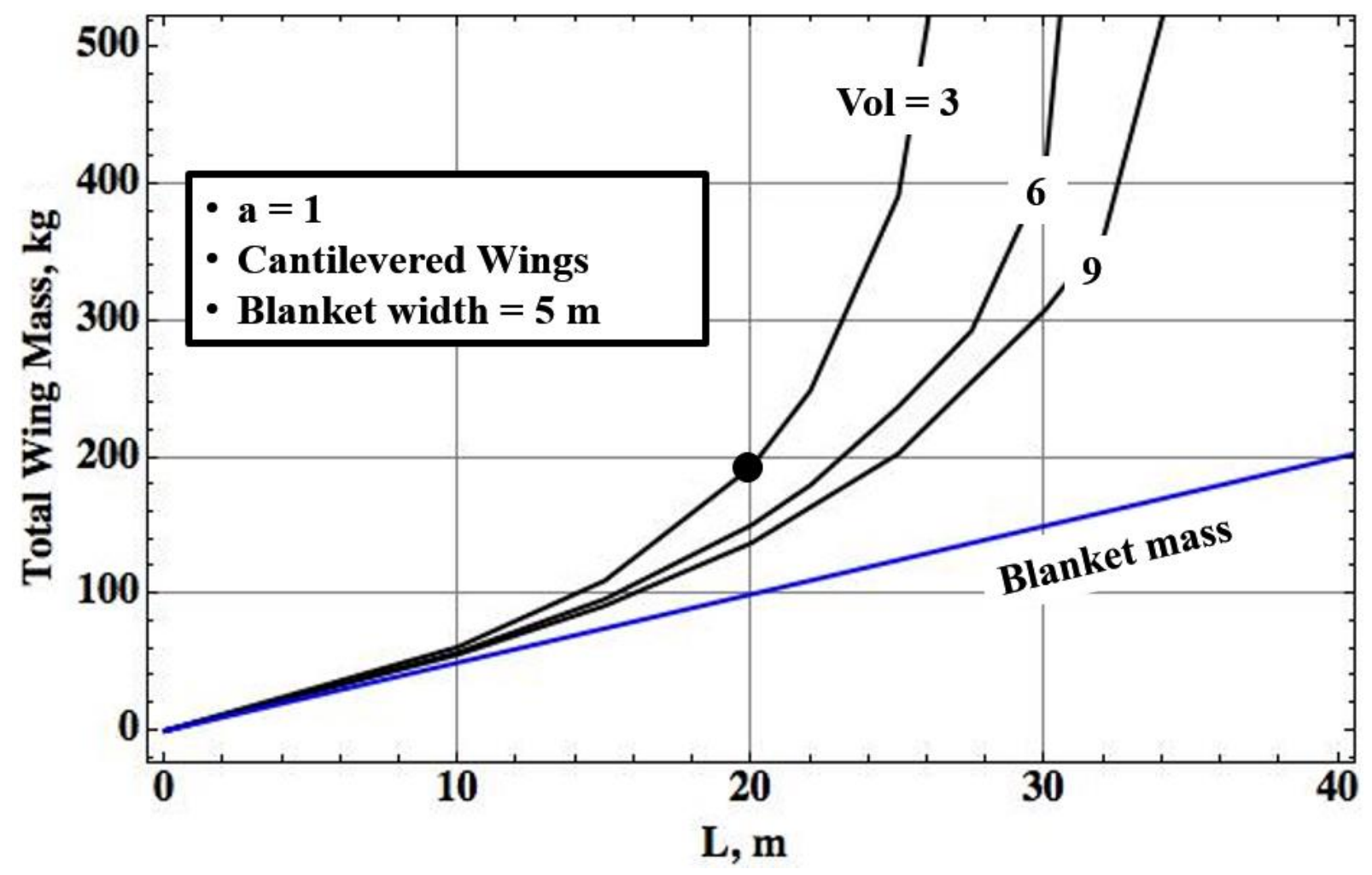

Figure 24. CTSA Structural Mass Reduces as Packaging Volume Increases. 

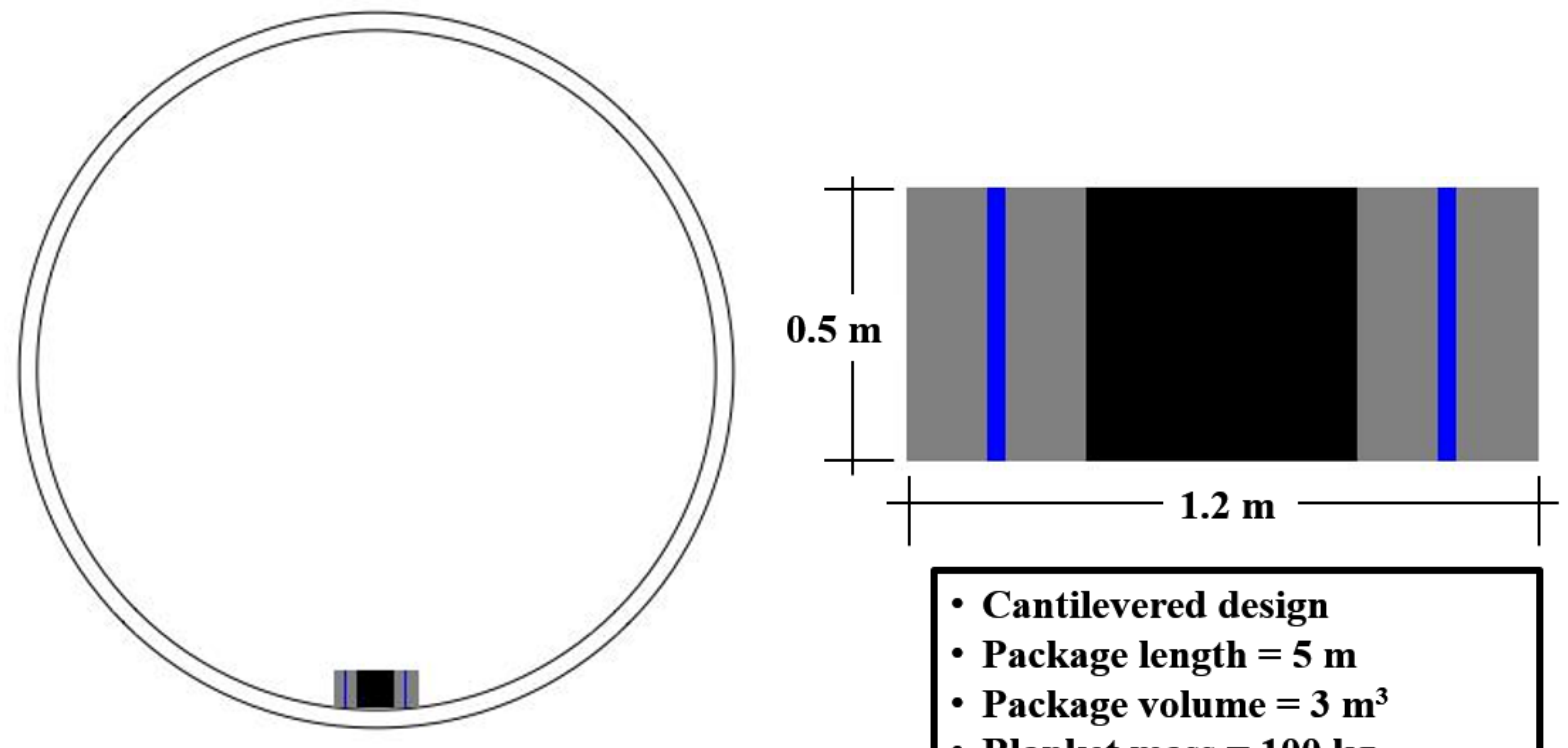

- Cantilevered design

- Package length $=5 \mathrm{~m}$

- Package volume $=3 \mathrm{~m}^{3}$

- Blanket mass $=100 \mathrm{~kg}$

- Structural mass $=93 \mathrm{~kg}$

- Cantilever frequency $=1.1 \mathrm{~Hz}$

Figure 25. $100 \mathrm{~m}^{2}$ CTSA in 10-m Shroud. Mass is Black Dot on Previous Three Figures. 